Article

\title{
Regional Equivalent Water Thickness Modeling from Remote Sensing across a Tree Cover/LAI Gradient in Mediterranean Forests of Northern Tunisia
}

\section{Hedia Chakroun ${ }^{1, *}$, Florent Mouillot $^{2}$ and Abdelaziz Hamdi ${ }^{3}$}

1 Ecole Nationale d'Ingénieurs de Tunis (ENIT), Laboratoire de Modélisation en Hydraulique et Environnement LR99ES19, Université de Tunis El Manar, 1002 Tunis, Tunisia

2 Centre d'Ecologie Fonctionnelle et Evolutive (CEFE), Unité Mixte de Recherche (UMR) 5175, Centre National de la Recherche Scientifique (CNRS)/Université de Montpellier/

Université Paul-Valéry Montpellier, Ecole Pratique des Hautes Etudes (EPHE)/Institut de Recherche pour le Développement (IRD), 1919 route de Mende, 34293 Montpellier Cedex 5, France; E-Mail: florent.mouillot@ird.fr

3 Laboratoire des Ressources Sylvo-Pastorales, Institut Sylvo Pastoral de Tabarka, 8110 Jendouba, Tunisia; E-Mail: abdelaziz.hamdi@iresa.agrinet.tn

* Author to whom correspondence should be addressed; E-Mail: hedia.chakroun@enit.rnu.tn; Tel.: +216-27-460-264; Fax: +216-71-872-729.

Academic Editors: Clement Atzberger and Prasad S. Thenkabail

Received: 24 July 2014 / Accepted: 8 December 2014 / Published: 10 February 2015

\begin{abstract}
The performance of vegetation indexes derived from moderate resolution imaging spectroradiometer (MODIS) sensors is explored for drought monitoring in the forests of Northern Tunisia; representing a transition zone between the Mediterranean Sea and the Sahara Desert. We investigated the suitability of biomass and moisture vegetation indexes for vegetation water content expressed by the equivalent water thickness (EWT) in a Mediterranean forest ecosystem with contrasted water budgets and desiccation rates. We

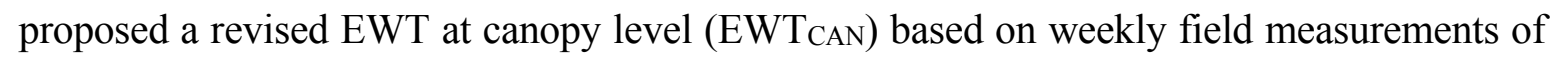
fuel moisture in seven species during the 2010 dry period, considering the mixture of plant functional types for water use (trees, shrubs and herbaceous layers) and a varying vegetation cover. MODIS vegetation indexes computed and smoothed over the dry season were highly correlated with the EWT CAN. The performances of moisture indexes Normalized Difference Infrared Index (NDII6 and NDII7) and Global Moisture Vegetation Index (GVMI6 and GVMI7) were comparable, whereas for biomass vegetation indexes, Normalized Difference
\end{abstract}


Vegetation Index (NDVI), Modified Soil Adjusted Vegetation Index (MSAVI) and Adjusted Normalized Difference Vegetation Index (ANDVI) performed better than Enhanced Vegetation Index (EVI) and Soil Adjusted Vegetation Index (SAVI). We also identified the effect of Leaf Area Index (LAI) on EWT CAN monitoring at the regional scale under the tree cover/LAI gradient of the region from relatively dense to open forest. Statistical analysis revealed a significant decreasing linear relationship; indicating that for LAI less than two, the greater the LAI, the less responsive are the vegetation indexes to changes in EWTCAN; whereas for higher LAI, its influence becomes less significant and was not considered in the

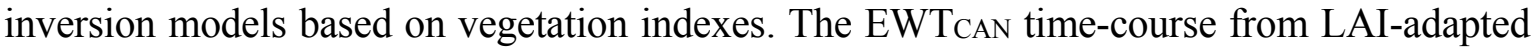
inversion models based on significantly-related vegetation indexes to EWT CAN $_{\text {showed close }}$ profiles resulting from the inversion models using NDVI, ANDVI, MSAVI and NDII6 applied during the dry season. The developed EWT CAN model from MODIS vegetation indexes for the study region was finally tested for its ability to capture the topo-climatic effects on the seasonal and the spatial patterns of desiccation/rewetting for keystone periods of Mediterranean vegetation functioning. Implications for further use in scientific developments or management are discussed.

Keywords: equivalent water thickness; biomass vegetation indexes; moisture vegetation indexes; moderate resolution imaging spectroradiometer (MODIS); leaf area index (LAI); Mediterranean forests

\section{Introduction}

Global to regional mapping and monitoring of drought is increasingly considered for food security assessment in agricultural lands [1] and for numerous ecosystem processes, such as carbon fluxes, plant productivity [2,3] or fire risk [4]. Various indexes for monitoring drought have been developed on the basis of meteorological datasets (see [5] for a review). Meanwhile, drought detection from remote sensing has been increasingly used since the 1990s in natural and cultivated ecosystems, particularly with the increasing temporal frequency of satellite images assessing land cover status (SPOT-VEGETATION, AVHRR and MODIS). Thus, temporal tracking of water content with spectral measures has been widely investigated, especially in water-limited regions (e.g., [6-9]). In ecosystems belonging to transition zones, as is the case for the North African forests representing transition zones between sub-humid Mediterranean forests and the semi-arid region at the northern edge of the Sahara, the accurate assessment of drought by the use of remote sensing and field observations is essential to determine the major constraints of such ecosystems. Vegetation indexes, as the result of empirical combinations of reflectance in various wavelengths, had contributed in detecting changes in biomass status as changes in chlorophyll activity (biomass vegetation indexes, BVI) and vegetation water content (moisture vegetation indexes, MVI). Various studies have investigated the combination of BVI and MVI, especially to assess drought conditions as interannual precipitation deficit/surplus [10] or, more specifically, its impact on vegetation water stress (e.g., [11,12]) or fire risk [4]. By combining the near-infrared (NIR) and shortwave infrared (SWIR) reflectances, variations induced by leaf internal 
structure and leaf dry matter content can be disentangled to improve the accuracy in retrieving the vegetation water content [13]. In turn, simulated and remotely-sensed reflectances in the SWIR domain can capture leaf water content at the canopy level $[11,14,15]$.

For biomass monitoring, various formulations of vegetation indexes were suggested, essentially to discriminate vegetation densities (combining reflectances in red and NIR bands), atmospheric effects (adding green and blue bands) and soil background adjustments. MVI computation is based on the combination of NIR and SWIR wavelengths (1200 to $2100 \mathrm{~nm}$ ), where the leaf water content plays a decisive role on the leaf reflectance [14]. We have summarized in Table 1 [15-20,25-28] the most used vegetation indexes, including their formulation and authors. BVI include, among others, NDVI (Normalized Difference Vegetation Index) and EVI (Enhanced Vegetation Index) for reducing atmospheric influence on the signal by the use of the blue spectral band, which does not saturate at high biomass compared to NDVI [16]. The Soil Adjusted Vegetation Index (SAVI) was developed to consider the reflectance of the complex soil-vegetation interaction via an adjustment factor $(\mathrm{L}=0.5)$, shown to reduce the soil signal to a non-significant noise for many vegetation density ranges [17]. Qi [18] proposed a modified SAVI, named Modified Soil Adjusted Vegetation Index (MSAVI), where the $\mathrm{L}$ factor is adjusted automatically to vegetation density (through an iterative function) to decrease the soil background effects on the vegetation signal. The Adjusted Normalized Difference Vegetation Index (ANDVI) combines both the adjustment of soil and atmospheric effects by the blue and green bands [19]. MVI indexes use multiple wavelengths in the middle infrared interval (B5 for the Normalized Difference Water Index (NDWI), B6 and B7 for the Normalized Difference Infrared Indexes (NDII6 and NDII7)) and for the Global Moisture Vegetation Indexes (GVMI6 and GVMI7), designed for reducing atmospheric effects [11,20,21]. Vegetation water status may be related to various indicators, such as "equivalent water thickness" EWT [13,22,23], allowing the leaf amount of water computation or the fuel moisture content (FMC), the mass of water contained within vegetation in relation to the dry mass [4]. Estimating EWT or FMC from remote sensing may be empirical (statistic-based) or physical, as indicated in [4]. Empirical methods compare field measurements of vegetation water content to MVI and BVI computed from multi-temporal satellite images, whereas physical models, known as radiative transfer models (RTM), use rather simulated reflectances or hyper spectral data. Optical remote sensing was also combined in other studies with passive microwave observations known to better succeed in canopy water content, integrating the contribution of trunk and branch water content (e.g., [24]).

Table 1. Biomass and moisture remote sensing vegetation indexes (bands correspond to the spectral interval of MODIS of Table 2). SAVI, Soil Adjusted Vegetation Index; ANDVI, Adjusted Normalized Difference Vegetation Index; NDII, Normalized Difference Infrared Index; GVMI, Normalized Difference Infrared Index; MSAVI, Modified Soil Adjusted Vegetation Index.

\begin{tabular}{cc}
\hline Biomass Vegetation Indexes & References \\
$\mathrm{NDVI}=(\mathrm{B} 2-\mathrm{B} 1) /(\mathrm{B} 2+\mathrm{B} 1)$ & {$[25,26]$} \\
$\mathrm{EVI}=2.5 \times(\mathrm{B} 2-\mathrm{B} 1) /(\mathrm{B} 2+6 \times \mathrm{B} 1-7.5 \times \mathrm{B} 3+1)$ & {$[16]$} \\
$\mathrm{SAVI}=(\mathrm{B} 2-\mathrm{B} 1)(1+\mathrm{L}) /(\mathrm{B} 2+\mathrm{B} 1+\mathrm{L}), \mathrm{L}=0.5$ & {$[17]$} \\
$\mathrm{MSAVI}=0.5 \times(2 \times \mathrm{B} 2+1)-\mathrm{SQRT}\left((2 \times \mathrm{B} 2+1)^{\wedge} 2-8 \times(\mathrm{B} 2-\mathrm{B} 1)\right)$ & {$[18]$} \\
$\mathrm{ANDVI}=(\mathrm{B} 2-\mathrm{B} 1+(1+\mathrm{L}) \times(\mathrm{B} 4-\mathrm{B} 3)) /(\mathrm{B} 2+\mathrm{B} 1+(1+\mathrm{L}) \times(\mathrm{B} 4+\mathrm{B} 3))$ & {$[19]$} \\
\hline
\end{tabular}


Table 1. Cont.

\begin{tabular}{cc}
\hline Moisture Vegetation Indexes & References \\
\hline NDWI $=(\mathrm{B} 2-\mathrm{B} 5) /(\mathrm{B} 2+\mathrm{B} 5)$ & {$[15]$} \\
NDII6 $=(\mathrm{B} 2-\mathrm{B} 6) /(\mathrm{B} 2+\mathrm{B} 6)$ & {$[27,28]$} \\
NDII7 $=(\mathrm{B} 2-\mathrm{B} 7) /(\mathrm{B} 2+\mathrm{B} 7)$ & {$[27,28]$} \\
GVMI6 $=[(\mathrm{B} 2+0.1)-(\mathrm{B} 6+0.02)] /(\mathrm{B} 2+0.1)+(\mathrm{B} 6+0.02)]$ & {$[20]$} \\
GVMI7 $=[(\mathrm{B} 2+0.1)-(\mathrm{B} 7+0.02)] /(\mathrm{B} 2+0.1)+(\mathrm{B} 7+0.02)]$ & {$[20]$} \\
\hline
\end{tabular}

Table 2. MODIS products and corresponding spectral bands.

\begin{tabular}{ccccc}
\hline \multicolumn{1}{c}{ Sensor } & Platform & Temp. Resolution & Spat Resolution & Product \\
\hline MOD15A2 & TERRA & 16 days & $1000 \mathrm{~m}$ & LAI \\
MYD15A2 & AQUA & 16 days & $1000 \mathrm{~m}$ & LAI \\
MCD15A2 & Combined TERRA/AQUA & 16 days & $1000 \mathrm{~m}$ & LAI \\
\hline & & & B1: $620-670 \mathrm{~nm}$ \\
& & & B2: $841-876 \mathrm{~nm}$ \\
MOD09A1 & TERRA & & \multirow{2}{*}{$500 \mathrm{~m}$} & B3: $459-479 \mathrm{~nm}$ \\
& & & B4: $545-565 \mathrm{~nm}$ \\
& & & B5: $1230-1250 \mathrm{~nm}$ \\
& & & B6: $1628-1652 \mathrm{~nm}$ \\
& & & B7: $2105-2155 \mathrm{~nm}$ \\
\hline
\end{tabular}

The performance of these indexes (BVI and MVI or combined ones) has been largely investigated to link vegetation water content to remotely-sensed data in various climates and ecosystems. In Mediterranean-type ecosystems, vegetation water content was shown to be linearly related to a combination of BVI and MVI using either high or coarse spatial resolution images [29-31]. In semi-arid ecosystems, Fensholt and Sandholt [14] found a strong relationship between the MVI and soil moisture (Sahelian zone in Africa); Ceccato et al. [32] and, more recently, Sow et al. [33] reported consistent relationships between field measurements of EWT and various BVI and MVI, allowing for a regional assessment of the seasonal dynamic of ecosystem dryness. Similar results were reported by [34] in the semi-arid region of Arizona.

However, the performance of VI as drought indicators was shown to be site-specific due to spatial differences in leaf and canopy characteristics, soil background, sensor characteristics and observation conditions [4]. Methods were then proposed to overcome this fact by modifying the linear regression between VI and EWT variables, accounting for the seasonal and interannual vegetation variability [4,30,35], as well as the species mixture and their related biophysical properties [36]. Considering that leaf area index (LAI) is an integrated proxy for canopy density and ecosystem water content capacity according to the ecohydrological equilibrium theory [37], canopy variables represented by LAI are also important parameters affecting the retrieval of water vegetation status from remote sensing vegetation indexes. Based on the Prospect simulation model [38] combined with canopy models, Ceccato et al. [20] showed that GVMI is suitable for retrieving vegetation water content when the LAI is equal to or greater than two due to the effect of soil background. Similar conclusions were reported in [33], who showed that the correlations between measured water vegetation content (EWT or FMC) and VI decreased moderately with decreasing aridity represented by increasing tree cover in the Sahel. Over areas with low LAI, there is a general consensus that red/NIR vegetation 
indexes saturate and, in turn, are less efficient than in foliar-water indexes for canopy water content estimation $[21,39,40]$.

From these identified contrasted performances of VI for monitoring vegetation moisture across ecosystems with varying LAI, main objectives of our study are: (1) making the assessment of the performance of BVI and MVI in a Mediterranean natural ecosystem at the transition zone with semi-arid climate conditions in Northern Africa, characterized by a heavy rainfall gradient, where vegetation is characterized by a low LAI and a tree density gradient associated with a significant shrub or grassland understory layer; (2) comparing EWT computed from seasonal field measurements collected in the dry season of the year 2010 across the climate gradient with VI computed from the MODIS sensor and testing the hypothesis that EWT is differentially correlated with VI, according to LAI; and (3) investigating the ability of the inversed model to reproduce comprehensive regional scale EWT and seasonal drought across the region.

\section{Material and Methods}

\subsection{Study Area}

The study area covers the Kroumirie forest territory $\left(2500 \mathrm{~km}^{2}\right)$, belonging to the narrow Mediterranean forest band in North Africa and located at the extreme north of Tunisia $\left(7^{\circ} 52^{\prime} \mathrm{E}-37^{\circ} 29^{\prime} \mathrm{N}\right.$ to $9^{\circ} 33^{\prime} \mathrm{E}-36^{\circ} 22^{\prime} \mathrm{N}$ ) between the Mediterranean Sea and the Sahara Desert (Figure 1). The region is mountainous with elevations ranging from $0 \mathrm{~m}$ on the northern coast to $1235 \mathrm{~m}$. Regional climate is Mediterranean, where precipitation is mainly distributed in autumn, winter and spring, while summers are dry, with a strong north/south gradient. The northern bound of the region is influenced by its proximity to the Mediterranean Sea with wet ( $800 \mathrm{~mm}$ annually) and mild temperatures, the upper mountains are very wet (1250 mm annual rainfall) with low winter temperatures and mild summers, and the southern floodplain is dry (360 mm annually) with warm temperatures. Vegetation is mostly an evergreen Quercus suber forest, with deciduous Quercus canariensis on the upper coldest sites and evergreen needle leaf Pinus pinaster on the coast. Understory or burnt areas in the region are covered by a maquis shrubland composed of Cistus monspeliensis, Erica arborea, Arbutus unedo, Phillyrea latifolia, Pistacia lentiscus and Calicotome villosa, among others.

\subsection{Field Measurements for Fuel Moisture Content (FMC)}

We conducted a campaign of field measurements for FMC in 2010 during the dry summer period from 1 June to 28 September, according to the "reseau hydrique" method for fire risk and Mediterranean forest conservation in southern France [41].

Seven permanent plots were selected across the regional climate gradient (Table 3). For each plot, we selected four biological indicators of vegetation dryness: the surface leaf litter, the shallow-rooted evergreen shrubs (Cistus monspeliensis, Myrtus communis), the deep-rooted shrubs (Erica arborea, Phillyrea arborea, Pistacia lentiscus) and the deep-rooted evergreen cork oak tree (Quercus suber). We selected three individuals per plot and three apical twigs per individual (15/20 g fresh weight). Fresh vegetation samples were collected every week, around 12:00 P.M. at the hottest point during the day, and were inserted in a stainless metal box, hermetically sealed with a sticky and elastic band. The 
boxes were then carried to the laboratory located in Tabarka (Institut Sylvo Pastoral). Unsealed, but non-open boxes (box and vegetation humid $\mathrm{BVH}$ ) were weighted with a precision balance. Once weighted, open boxes were inserted in an oven at $60{ }^{\circ} \mathrm{C}$ for $24 \mathrm{~h}$ and weighted again (box and vegetation dry BVD). Vegetation was extracted from the box, and the empty dry box was weighted on its own (BD). Fuel moisture content (\% dry weight) was estimated according to Equation (1) (Figure 2).

$$
F M C=\frac{B V H-B V D}{B V D-B D}
$$

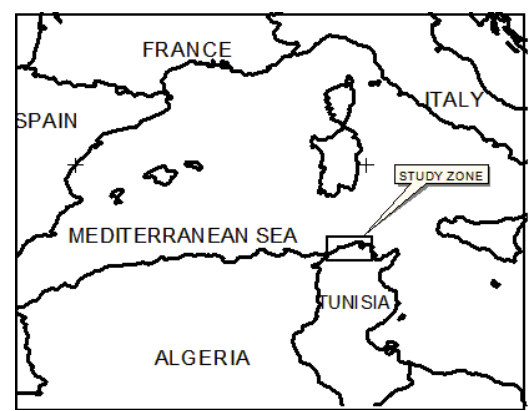

(a)

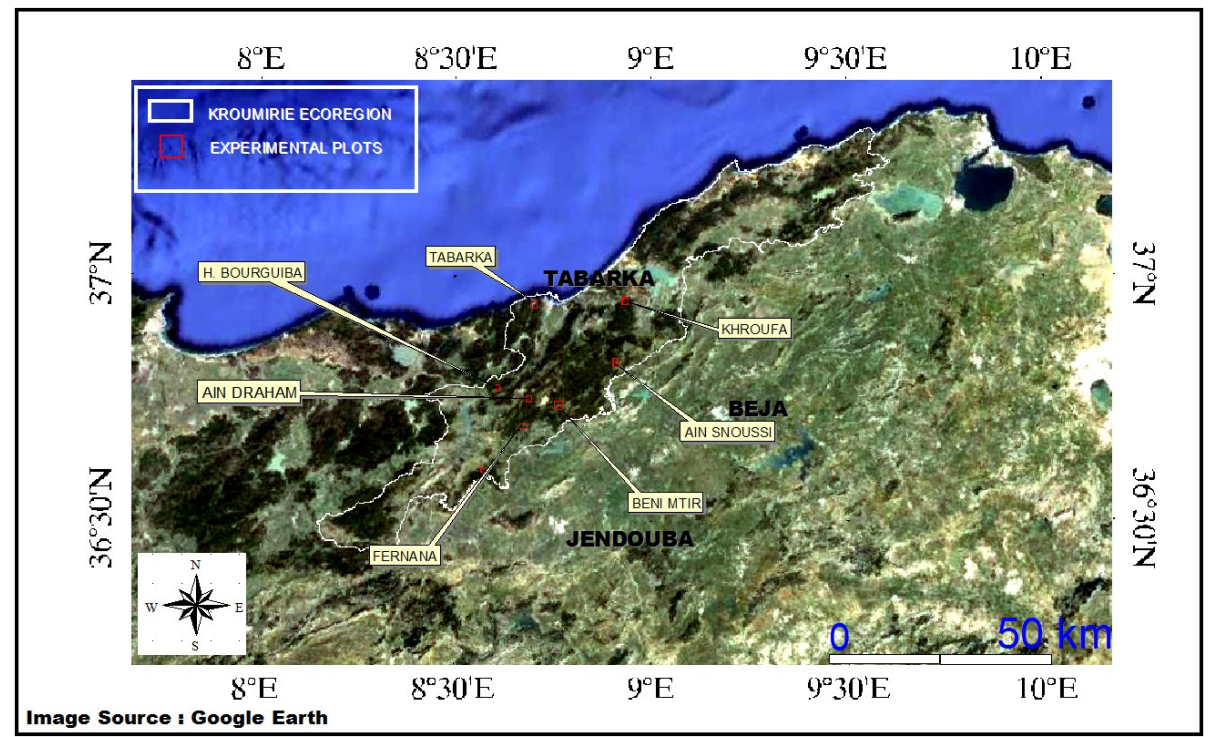

(b)

Figure 1. (a) General localization of study area. (b) Kroumirie ecoregiona and experimental plot localization.

Table 3. Study plot location, elevation and vegetation characteristics. Species are composed of the: (1) tree layer (Qs, Quercus suber, Leaf mass area (LMA) $=0.143 \mathrm{kgC} \cdot \mathrm{m}^{-2}$ ); (2) shrub layer (Ea, Erica arborea, LMA $=0.114 \mathrm{kgC} \cdot \mathrm{m}^{-2} ; \mathrm{Cm}$, Cistus monspeliensis, LMA $=0.149 \mathrm{kgC} \cdot \mathrm{m}^{-2} ;$ Au, Arbutus unedo, LMA $=0.146 \mathrm{kgC} \cdot \mathrm{m}^{-2} ; \mathrm{Phl}$, Phillyrea latifolia, LMA $=0.183 \mathrm{kgC} \cdot \mathrm{m}^{-2} ; \mathrm{Pl}$, Pistacia lentiscus, LMA $=0.182 \mathrm{kgC} \cdot \mathrm{m}^{-2}$; Mc, Myrtus communis, LMA $=0.183 \mathrm{kgC} \cdot \mathrm{m}^{-2}$ ); (3) Herbaceous layer litter (L, LMA= average $\left(\mathrm{LMA}_{i}\right)$, where " $i$ " are the species actually present in the plot). LAI $\mathrm{Iin}_{\mathrm{LA}} / \mathrm{LA}$ max derived from corrected LAI-MODIS values corresponding to the field campaign in 2010.

\begin{tabular}{ccccccc}
\hline Plots & Longitude & Latitude & Elevation $(\mathbf{m})$ & \% Cover & LAI $_{\min } / \mathbf{L A I}_{\max }$ & Species \\
\hline Ain Draham & $8^{\circ} 41^{\prime} 14.6^{\prime \prime}$ & $36^{\circ} 45^{\prime} 04.1^{\prime \prime}$ & 643 & 80 & $2.77 / 2.90$ & Qs, Ea, Cm, Au, L \\
Ain Snoussi & $8^{\circ} 54^{\prime} 50.1^{\prime \prime}$ & $36^{\circ} 49^{\prime} 41.3^{\prime \prime}$ & 452 & 70 & $2.04 / 2.27$ & Qs, Ea, Mc, Au, L \\
Beni Mtir & $8^{\circ} 44^{\prime} 59.1^{\prime \prime}$ & $36^{\circ} 45^{\prime} 02.1^{\prime \prime}$ & 322 & 50 & $0.87 / 1.10$ & Qs, Ea, Cm, Phl, L \\
Fernana & $8^{\circ} 40^{\prime} 38.0^{\prime \prime}$ & $36^{\circ} 41^{\prime} 29.6^{\prime \prime}$ & 382 & 60 & $1.94 / 2.67$ & Qs, Ea, Cm, Phl, L \\
Hammam & $8^{\circ} 36^{\prime} 34.0^{\prime \prime}$ & $36^{\circ} 46^{\prime} 31.5^{\prime \prime}$ & 311 & 50 & $1.84 / 2.21$ & Qs, Ea, Cm, Pl, L \\
Bourguiba & & & 175 & 60 & $1.10 / 1.45$ & Qs, Ea, Cm, Phl, L \\
Khroufa & $8^{\circ} 56^{\prime} 09.7^{\prime \prime}$ & $36^{\circ} 57^{\prime} 13.1^{\prime \prime}$ & 195 & 70 & $2.10 / 2.70$ & Qs, Ea, Cm, Mc, Au, L \\
Tabarka & $8^{\circ} 42^{\prime} 10.0^{\prime \prime}$ & $36^{\circ} 56^{\prime} 48.1^{\prime \prime}$ & 195 & & &
\end{tabular}




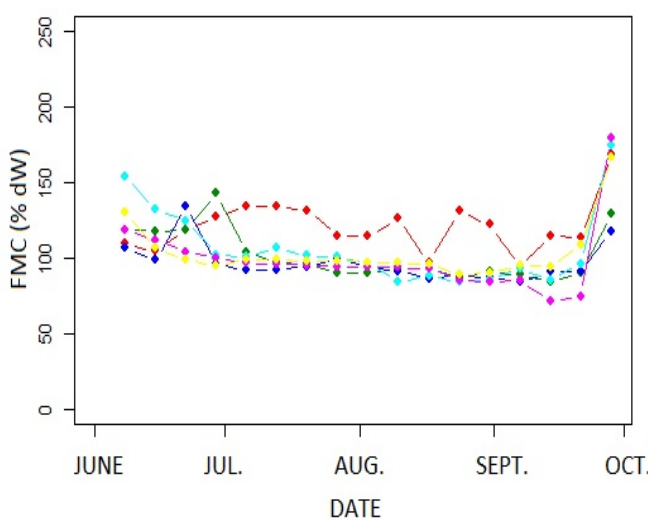

(a)

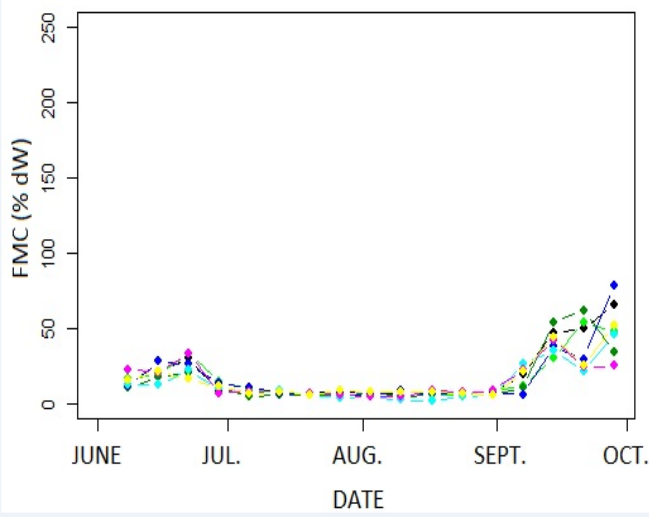

(c)

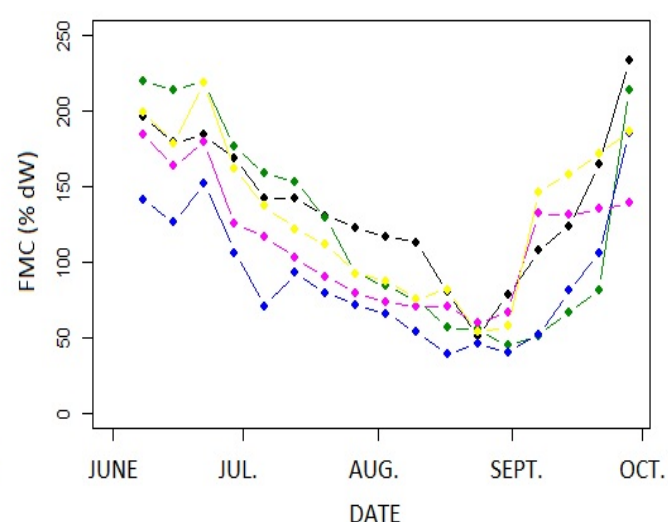

(b)

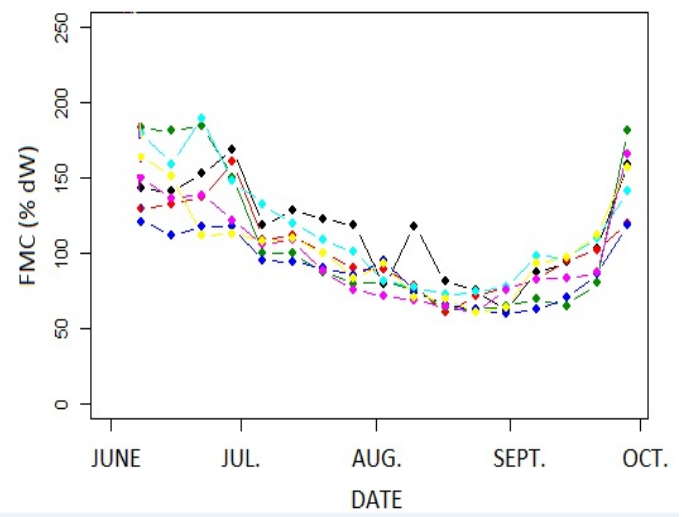

(d)

Figure 2. Weekly estimates of fuel moisture content (FMC) for (a) Quercus suber, (b) Cistus monspeliensis, (c) Litter, (d) Erica arborea and between June 1 and September 28, 2010, for study plots Ain Draham (black), Ain Snoussi (red), Beni Mtir (green), Fernana (blue), Hammam Bourguiba (cyan), Khroufa (magenta) and Tabarka (yellow).

\subsection{Equivalent Water Thickness Calculation}

A formulation of the equivalent water thickness (EWT) was suggested by [28] (Equation (2)) at the leaf level, to quantify the equivalent depth of water (in $\mathrm{mm}$ ) contained in the plants, as relevant information for remote sensing studies using NIR and SWIR bands [4]. At the canopy level, EWT is commonly computed by multiplying FMC by the amount of leaves per unit of ground area (LAI) and is defined as a hypothetical thickness of a single layer of water multiplied by the number of layers determined by the LAI [20].

$$
E W T=\frac{F M-D M}{10^{3} \rho_{W} L A}
$$

$E W T$ : equivalent water thickness of leaves $(\mathrm{mm}) ; F M$ : fresh matter $(\mathrm{kg}) ; D M$ : dry matter $(\mathrm{kg})$; $L A$ : leaf area $\left(\mathrm{m}^{2}\right) ; \rho_{w}$ : density of pure water $\left(1000 \mathrm{~kg} \cdot \mathrm{m}^{-3}\right)$.

Equation (2) is valid when the ecosystem is homogeneous in terms of vegetation functioning, the desiccation rate of plants and the seasonality of LAI through similar phenology. Our ecosystem is composed of evergreen trees with tree cover ranging from $25 \%$ to $100 \%$, with an understory of evergreen shrubs and a ground layer covered by annual herbaceous species drying and dying off at the end of spring. We are confronted here with the peculiar aspect that: (1) the surface litter, the shrub 
layer and the tree layer have contrasted water budget functioning; and (2) the distribution of cover within each vegetation type varies spatially across the region. We reformulated Equation (2) into Equation (3) to account for EWT at canopy level EWT CAN $_{\text {in }}$ our mixed ecosystem composed of N species, admitting each a leaf mass area $\mathrm{LMA}_{\mathrm{i}}$.

$$
E W T_{C A N}=\frac{1}{\rho_{W}} \frac{1}{N} \sum\left(\frac{F M_{i}-D M_{i}}{L A_{i}}\right)
$$

For each species " $i$ ", Equations (4) and (5) give the $\mathrm{FMC}_{\mathrm{i}}\left(\% \mathrm{gH}_{2} \mathrm{O} \cdot \mathrm{gC}^{-1}\right)$ and the $\mathrm{LMA}_{\mathrm{i}}\left(\mathrm{kgC} \cdot \mathrm{m}^{-2}\right)$.

$$
\begin{gathered}
F M C_{i}=\frac{F M_{i}-D M_{i}}{D M_{i}} \\
L M A_{i}=\frac{D M_{i}}{L A_{i}}
\end{gathered}
$$

When inserting Equations (4) and (5) in Equation (3), we finally get Equation (6) giving $E W T_{C A N}(\mathrm{~m})$.

$$
E W T_{C A N}=\frac{1}{\rho_{W}} \frac{1}{N} \sum\left(F M C_{i}\right)\left(L M A_{i}\right)
$$

As we have a unique LAI value for the whole MODIS pixel, which mixes tree/shrub LAI and herbaceous LAI, we decomposed LAI-MODIS based on previous observations that LAI-MODIS follows a seasonal pattern not matching the actual LAI variations measured on site for evergreen Mediterranean trees [42]. We then stated that minimum LAI-MODIS is close to tree/shrub LAI when the herbaceous layer is dry, so that the seasonal variation between remotely-sensed LAI and LAI min characterizes the herbaceous LAI variations. We derived Equation (7) from Equation (6) by partitioning the herbaceous and the tree components of the pixel according to tree cover COV. Tree/shrub leaf area was estimated as $\left[\mathrm{COV} \times \mathrm{LAI}_{\mathrm{min}}\right]$ all along the year, and the litter LAI variations were estimated as the $\left[(1-\mathrm{COV}) \times\left(\mathrm{LAI}-\mathrm{LAI}_{\min }\right)\right]$.

$$
E W T_{C A N}=\frac{10^{-4}}{\rho_{W}}\left[(C O V) \times\left(L A I_{\text {min }}\right)\left(\frac{\sum_{i=1}^{N}\left(F M C_{i}\right) \times\left(L M A_{i}\right)}{N}\right)+(1-(C O V)) \times\left((L A I)-\left(L A I_{\min }\right)\right) \times\left(F M C_{L I T T E R}\right) \times\left(L M A_{\text {LITTER }}\right)\right]
$$

$E W T_{C A N}$ : equivalent water thickness of the canopy in each plot $\left(\mathrm{gH}_{2} \mathrm{O} \cdot \mathrm{cm}^{-2}\right) ; L A I$ : leaf area index $\left(\mathrm{m}^{2} \cdot \mathrm{m}^{-2}\right)$; LAImin: minimal leaf area index during the dry season $\left(\mathrm{m}^{2} \cdot \mathrm{m}^{-2}\right) ; F M C_{i}$ : FMC of each species $\left(\% \mathrm{gH}_{2} \mathrm{O} \cdot \mathrm{gC}^{-1}\right) ;$ FMC LITTER: FMC of litter $\left(\% \mathrm{gH}_{2} \mathrm{O} \cdot \mathrm{gC}^{-1}\right) ; L M A$ : leaf mass area (inverse of SLA: specific leaf area) of each species $\left(\mathrm{kgC} \cdot \mathrm{m}^{-2}\right)$; LMALITTER: leaf mass area of litter estimated by the average of $\mathrm{LMA}_{i}$ of species present in the plot $\left(\mathrm{kgC} \cdot \mathrm{m}^{-2}\right)$; $\mathrm{COV}: \%$ vegetation cover of each plot (estimated visually from Google Earth images); N: total number of species in each plot; $\rho_{\mathrm{w}}$ : density of pure water $\left(=1000 \mathrm{~kg} \cdot \mathrm{m}^{-3}\right)$.

\subsection{MODIS Images Processing}

We used MODIS time series of preprocessed LAI (freely available at [43]) from 1-km resolution of 16-day composite products, MOD15A2 (TERRA sensor), MYD15A2 (AQUA sensor), MCD15A2 (combined TERRA/AQUA), and the bidirectional reflectance (MOD09A1) 500-m resolution of 8-day 
composite product (Table 2). We compared the three MODIS LAI products to measured plots of LAI over the study region of Kroumirie in 2006 (refer to [44] for a detailed explanation of LAI measurements). The least RMSE was obtained with TERRA (RMSE $=2.36$ ), compared to AQUA $(\mathrm{RMSE}=3.24)$ and to TERRA/AQUA $(\mathrm{RMSE}=3.49)$. However, the RMSE value remained high even for the TERRA product, especially for highly-covered plots (NDVI > 0.6). Thus, we suggested a calibration method for the TERRA-MODIS LAI product based on both ground measurements and SPOT images that were used as ground truth LAI maps (refer to [44] for the calibration process details).

From visualization and profile examination, we noticed important noise due to both cloud contamination (in the wet season) and sensor defaults that had to be removed from all reflectance bands of the MOD09A1 and the derived indexes; we also noticed a systematic noise (strips) in B5

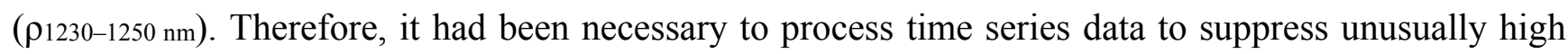
or low VI values. We used the Timesat software smoothing tool $[45,46]$ to overcome MODIS product imperfections and contaminated images. This tool comprises two main processing stages. First, a preliminary processing is made to remove spikes and outliers due to clouds or imperfections of the sensor; then a filtering method is used. Two types of filtering methods are proposed in Timesat software: (1) Local model functions (the asymmetric Gaussians function or the double logistic function) that are being fit to data (VI at a given time " $t$ ") in intervals around maxima and minima in the time-series; (2) adaptive Savitzky-Golay method where each $\operatorname{VI}(t)$ value is replaced by a linear combination of nearby values for $(2 n+1)$ points, with " $n$ " being the number of time steps preceding or following the time " $t$ " [47]. The filter is adaptive since the window size " $n$ " can be adjusted during the processing if there is a large variation in an interval around a given VI value; in this case, the filtering is redone with a smaller " $n$ " size window. This latter filter has been used with success in minimizing noise in NDVI $[48,49]$. Our time series data of various VI had been processed within the Timesat software tool; we also find a better performance of the adaptive Savitzky-Golay method over the local model functions. Thus, the smoothing significantly corrected the abrupt changes in VI, except for NDWI computed from B2 and B5 bands; this latter band represents a systematic strip noise over the smoothed images, and thus, NDWI was further excluded from the analysis.

Weekly reflectances MODIS images corresponding to a 2010 field campaign were processed as follows: we localized field plots on the referenced MODIS images and chose a relatively homogeneous area surrounding the plot (using Google Earth) to make comparisons between remotely-sensed data and EWTCAN based on field measurements. Then, within each region of interest (ROI), biomass and moisture indexes (BVI and MVI) were calculated in terms of basic statistics of the existing pixels (min, max, average, standard deviation).

\subsection{Statistical Analysis}

Relationships between EWT $\mathrm{CAN}_{\mathrm{N}}$ and VI were evaluated by linear regressions with the "Lm" function in " $R$ cran" software, from which we derived the intercept, slope, their corresponding $p$-values and $R^{2}$ coefficients. Regressions were performed for EWT $_{\text {CAN }}$ data assembled at the regional level (All Plots) and for each of the 7 study sites (Plot). We then evaluated the linear regression between plot-level regression slopes and LAI of these plots with the same statistical tool, to derive the intercept, slope, their $p$-values and $R^{2}$ for each remotely-sensed variable. 
Statistical models at the All Plot and Plot level were then inversed to estimate EWTCAN at the plot level and at the landscape level using 8-day MODIS image time series VI. Root mean squared errors

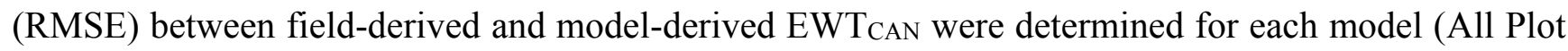
and Plot with LAI-based relationships).

\section{Results and Discussion}

\subsection{Spatial and Temporal Relationship between EWT $T_{C A N}$ and Remotely Sensed vegetation indexes (VI)}

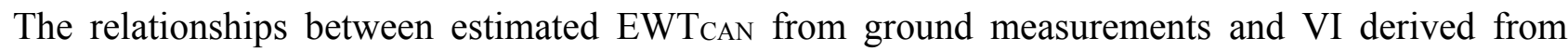
MODIS spectral bands are shown in Figure 3, with their corresponding regression analysis statistics (Table 4). In general, all indexes performed satisfactorily well, except for EVI and SAVI, which provided the lowest correlations. All tested MVI show strong relationships $\left(R^{2}>0.60\right)$, whereas NDVI, MSAVI and ANDVI show the strongest relation amongst the BVI (Table 4a). As a regional pattern (analysis of All Plots, Table 4a), we observe that, across the LAI gradient of the selected study plots with LAI varying between 1.10 and 2.90 (range of maximum values in Table 3), EWTCAN vary between 0 and $0.05 \mathrm{~g} \cdot \mathrm{cm}^{-2}$, and all VI significantly follow a positive linear relationship with EWTCAN ( $R^{2}$ varying from 0.43 for SAVI to 0.73 for NDII7, MSAVI and ANDVI), a result consistent with previously reported analysis for natural and cultivated vegetation $[11,23,50]$.
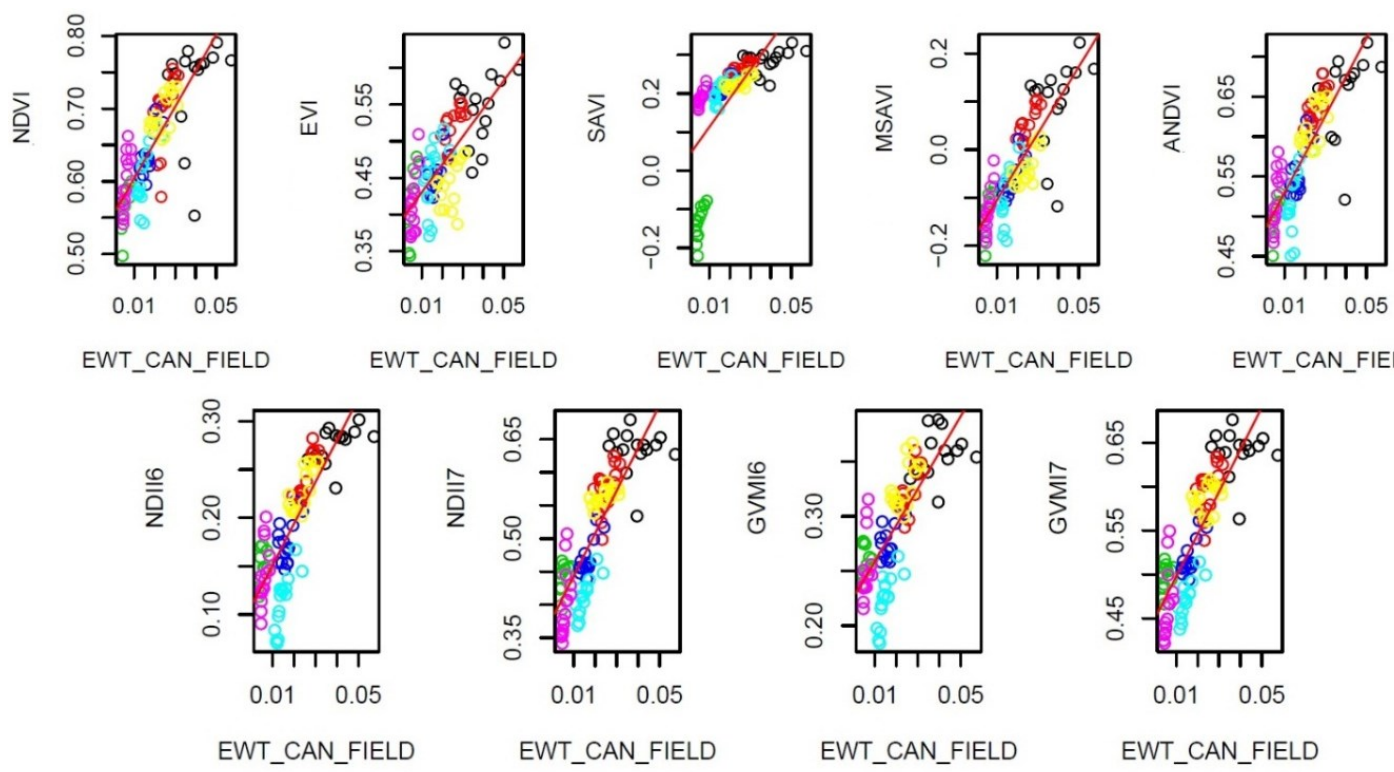

○ AIN DRAHAM OAIN SNOUSSI OBENI MTIR OFERNANA

- HAMMAM BOURGUIBA OKHROUFA

TABARKA

Figure 3. Regional (All Plots) relationship between equivalent water thickness at the canopy level (EWTCAN; $\mathrm{g} \cdot \mathrm{cm}^{-2}$ ) and MODIS-VI indexes with the resulting fitted linear model (red line). Colored dots represent each of the seven study plots.

Based on these observations, we then tested if the plot-level seasonal course of EWT CAN follows the same linear relationship as the generic spatial regional relationship (Table $4 \mathrm{~b}$, regressions by plot), so that this latter one can be used to estimate the seasonal variation of EWTCAN. We found most values of $R^{2}$ to be much lower at the plot level, with the lowest value observed for the "Ain Draham" plot 
characterized by the highest LAI (Table 3). We noticed from Figure 3 that "Beni Mtir" is away from the general trend of the relationship for SAVI, which includes all of the sites. Actually, the SAVI general correlation (Table $4 \mathrm{a}$ ) is the lowest, with $R^{2}=0.43$ quantifying this anomaly. This could be explained by the low LAI of "Beni Mtir" (Table 3) and the fact that the SAVI is a precisely sensitive index to soil effect. We also noticed that "Hammam Bourguiba" and "Khroufa" sites present somehow parallel scatterplots with the various indexes (Figure 3), but they admit different $R^{2}$ values (Table $4 \mathrm{~b}$ ), meaning that the dispersion of points around the trend line is different for these two sites while having the same slope. Globally, as we found most values of $R^{2}$ to be much lower at the plot level, our hypothesis that the regional regression can be applied to estimate the temporal course of EWTCAN across the season is then rejected.

Table 4. (a) Regression of linear relation (EWTCAN, VI) by plot; (b) regression of linear relation (EWTCAN, VI) for all plots; (c) regression between LAI and Slope (A) for all plots. $p \_$inter and $p \_$slope are $p$-values of intercept and slope.

\begin{tabular}{|c|c|c|c|c|c|c|c|c|c|}
\hline All Plots & NDVI & EVI & SAVI & MSAVI & ANDVI & NDII6 & NDII7 & GVMI6 & GVMI7 \\
\hline \multicolumn{10}{|c|}{ (a) Regression Summary Table for $\left(\mathrm{EWT}_{\mathrm{CAN}}, \mathrm{VI}\right)$ Relationship } \\
\hline Intercept (B) & 0.56 & 0.39 & 0.04 & -0.17 & 0.48 & 0.11 & 0.38 & .23 & 0.45 \\
\hline Slope (A) & 4.91 & 3.80 & 7.40 & 6.93 & 4.84 & 4.31 & 6.43 & 3.31 & 4.82 \\
\hline$R^{2}$ & 0.68 & 0.58 & 0.43 & 0.73 & 0.73 & 0.71 & 0.73 & 0.63 & 0.71 \\
\hline$p \_$inter & $<0.01$ & $<0.01$ & 0.03 & $<0.01$ & $<0.01$ & $<0.01$ & $<0.01$ & $<0.01$ & $<0.01$ \\
\hline$p \_$slope & $<0.01$ & $<0.01$ & $<0.01$ & $<0.01$ & $<0.01$ & $<0.01$ & $<0.01$ & $<0.01$ & $<0.01$ \\
\hline \multicolumn{10}{|c|}{ (b) $R^{2}$ for Plot Level (EWT $\left.{ }_{\mathrm{CAN}}, \mathrm{VI}\right)$ Relationship } \\
\hline Ain Draham & 0.05 & 0.17 & 0.14 & 0.11 & 0.09 & 0.25 & 0.00 & 0.08 & 0.00 \\
\hline Ain Snoussi & 0.35 & 0.43 & 0.60 & 0.62 & 0.60 & 0.84 & 0.31 & 0.51 & 0.30 \\
\hline Beni Mtir & 0.42 & 0.48 & 0.51 & 0.51 & 0.66 & 0.34 & 0.21 & 0.12 & 0.15 \\
\hline Fernana & 0.62 & 0.21 & 0.52 & 0.58 & 0.54 & 0.27 & 0.62 & 0.28 & 0.62 \\
\hline Hammam Bourguiba & 0.60 & 0.29 & 0.47 & 0.48 & 0.54 & 0.67 & 0.71 & 0.58 & 0.68 \\
\hline Khroufa & 0.65 & 0.47 & 0.82 & 0.84 & 0.66 & 0.34 & 0.40 & 0.17 & 0.34 \\
\hline Tabarka & 0.38 & 0.21 & 0.50 & 0.49 & 0.40 & 0.61 & 0.40 & 0.37 & 0.06 \\
\hline \multicolumn{10}{|c|}{ (c) Regression Summary Table for the (LAI, Slope (A)) Relationship } \\
\hline Intercept $(\beta)$ & 20.88 & 22.80 & 19.19 & 29.68 & 19.98 & 12.47 & 18.81 & 7.44 & 13.00 \\
\hline Slope $(\alpha)$ & -7.06 & -8.56 & -7.41 & -10.39 & -6.92 & -3.95 & -6.98 & -2.14 & -4.78 \\
\hline$R^{2}$ & 0.65 & 0.87 & 0.88 & 0.76 & 0.71 & 0.67 & 0.53 & 0.42 & 0.46 \\
\hline$p \_$inter & $<0.01$ & $<0.01$ & $<0.01$ & $<0.01$ & $<0.01$ & $<0.01$ & 0.02 & 0.02 & 0.03 \\
\hline$p$ slope & 0.03 & $<0.01$ & $<0.01$ & 0.01 & 0.02 & 0.02 & 0.06 & 0.11 & 0.09 \\
\hline
\end{tabular}

We then hypothesized that the slopes of the regression between EWTCAN and VI were correlated to LAI. Table $4 \mathrm{c}$ represents the slopes, intercepts, $p$-values and $R^{2}$ of the (LAI, Slope(A)) relationship for each study plot, with Slope (A) being the slope of the (EWTCAN, VI) linear relation given in Table 4a. Figure 4 represents the relationship between LAI study plots and the slope of the plot-level (EWTCAN, VI) relationship. First, we found that for LAI $\leq 2$, the decreasing relation is significative at the 0.05 threshold (black dots in Figure 4) and becomes not significative for LAI greater than two. This suggests that for sparse vegetation $(\mathrm{LAI} \leq 2)$, EWTCAN is driven by the LAI effect. For all BVI, we observed a significant decreasing linear relationship at the 0.05 threshold, indicating that the 
greater the LAI, the less responsive are VI to changes in EWTCAN. However, for MVI, the (LAI, Slope (A)) relationship is only significant for NDII6. This was also reported in [20], who mentioned that the GVMI6 (from simulated reflectances) is suitable for retrieving vegetation water content when the LAI is equal to or greater than two, which is not the case in all of the observed sites in the study region. In light of our experimental results, we can conclude that BVI are correlated with EWTCAN, and these relations are also driven by the LAI pattern for sparse vegetation (LAI $\leq 2)$ that ensures the ecosystem's water carrying capacity (or maximum EWT $\mathrm{CAN}_{\text {); }}$ only NDII6 represents this pattern amongst the tested MVI.

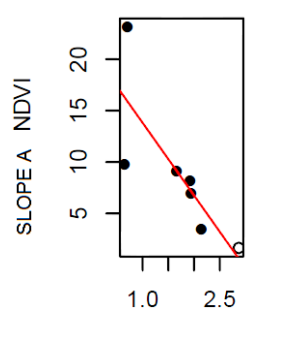

LAl

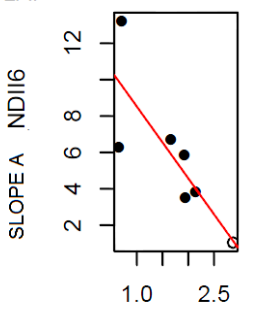

LAI

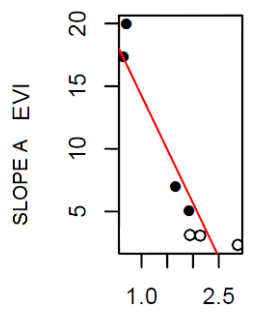

LAI

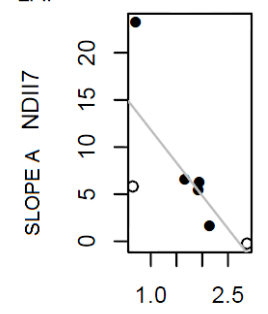

LAI

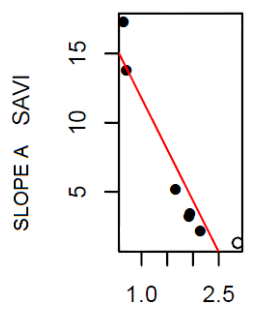

LAI

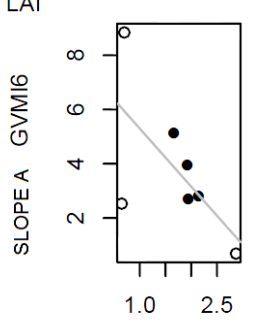

LAI
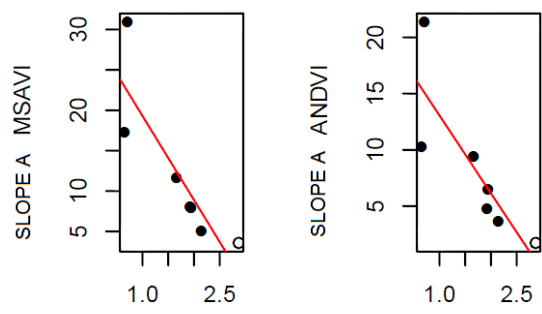

LAI

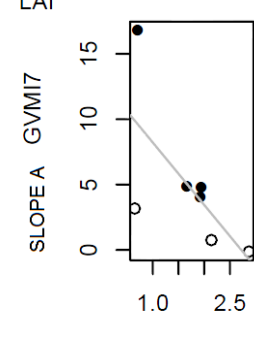

LAI

Figure 4. Relationship between LAI plot (X-axis) level and Slope(A) of (EWTCAN, VI) (Y-axis). (Red line, significant relationship $p$-value $<0.05$; grey line, no significant relationship). Black dots represent significant plot-level relationships, and empty dots represent non-significant relationships at the 0.05 threshold for $p$-values.

Our peculiar pattern of LAI-dependent (EWT CAN, $\mathrm{VI})$ relationship points out the heterogeneous plant functioning in Mediterranean-type ecosystems. We measured contrasted species' desiccation rates, including litter, in accordance with previous studies on Mediterranean vegetation [51-53]. These contrasted species-specific fuel moistures could partly explain the non-linearities of the (EWTCAN, VI) relationship as a response of LAI-dependent differential functional diversity. We might also wonder if the seasonal variations of LMA (see [54] for a review), as an increase in the canopy as a function of leaf aging [55] or the LMA decrease in the litter layer as a function of decomposition [56], could have substantially affected EWTCAN, so we calculated with a constant LMA, as already pointed out in $[4,20]$, but which is hardly ever considered in regional-scale EWTCAN assessment from remote sensing. Indeed, an increase in LMA for aged leaves would enhance EWTCAN at the end of the dry season and, in turn, increase the (EWTCAN, VI) slope for high LAI sites. On the contrary, in lower LAI sites more dominated by grasslands, a decrease in litter LMA along the season could reduce EWTCAN

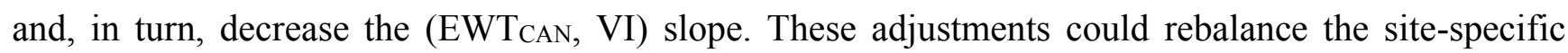
(EWT CAN VI) relationships to the generic one to be used both spatially and temporally. Our approach relying on a plot-level (LAI, Slope(A)) relationship could then readjust EWTCAN, so we estimated with 
fixed LMA, and in turn, this would prevent time-consuming LMA measurements for each measured FMC. This hypothesis should be further evaluated with field campaigns.

\subsection{Model Inversion for Regional EWTCAN}

Based on the highest correlations $\left(R^{2}>0.60\right)$, model retrieving of EWT CAN using VI is proposed. We called the MOD1 and MOD2 models, respectively, non-integrating and integrating LAI effects in

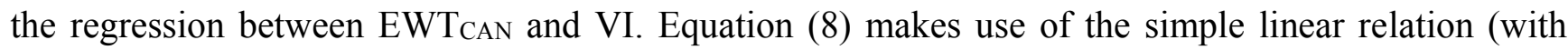
$R_{1}^{2}$ ) between VI and EWT $\mathrm{CAN}$, where "A" and "B" are, respectively, the slope and intercept (Table 4a). Equation (9) uses the slope varying with vegetation density expressed by a linear relation (with $R_{2}^{2}$ ) with a decreasing slope when LAI increases (intercept and slope " $\alpha$ " and " $\beta$ " from Table $4 c$ and intercept "B" from Table 4a). As stated earlier (Section 3.1), the LAI pattern influences the retrieval of

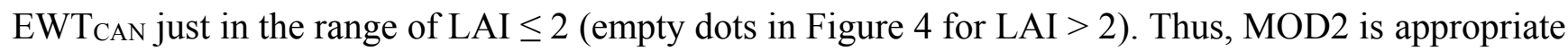
for sparse vegetation, whereas MOD1 is proposed for LAI $>2$.

$$
\begin{gathered}
E W T_{C A N}-M O D 1=\frac{1}{A}(V I)-\frac{B}{A} \\
E W T_{C A N}-M O D 2=\frac{(V I)-B}{\alpha(L A I)+\beta}
\end{gathered}
$$

$V I$ : vegetation index (BVI or MVI); $A, B$ : slope and intercept from Table $4 \mathrm{a} ; \alpha, \beta$ : slope and intercept from Table $4 \mathrm{c}$.

Table 5 summarizes inversion models for EWTCAN estimation from BVI and MVI indexes and the conditions of use of these models to obtain positive values of EWTCAN (last column). The comparison of the two models' performance was carried out by the total RMSE computation showing the dispersion of both models in front of EWTCAN_FIELD and relative to the 1:1 line (Figure 5). Inversion models based on VI/LAI (MOD2, Equation (9)) having the strongest $R_{1}{ }^{2}$ and $R_{2}{ }^{2}$ at the same time produce slightly lower RMSE (underlined $R_{1}{ }^{2}, R_{2}{ }^{2}$ and RMSE in Table 5) compared to MOD1. This could be explained by the fact that most of the plots admit $\mathrm{LAI} \leq 2$, and consequently, their EWTCAN is more appropriately simulated by MOD2 rather than MOD1.

The effect of LAI integration in the inversion model is highlighted in Figure 6 (comparison of inversion MOD1 and MOD2 for VI with both $R_{1}^{2}$ and $R_{2}^{2}>0.60$ ), showing that for a given value of VI, corresponding EWTCAN is decreasing as vegetation LAI is decreasing (for LAI $\leq 2$ ). Consequently, at this range of LAI, EWTCAN is overestimated if it is determined from the VI-based inversion model (MOD1). Our results suggest that for a canopy characterized by reduced tree cover, LAI highly affects

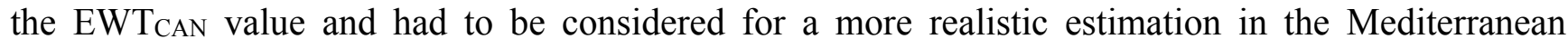
natural vegetation areas to avoid overestimated EWTCAN. 
Table 5. Inversion models for EWTCAN $\left(\mathrm{g} \cdot \mathrm{cm}^{-2}\right)$ retrieval from biomass vegetation indexes (BVI), moisture vegetation indexes (MVI) and LAI. $R^{2}>0.60$ and the corresponding RMSE are underlined. Conditions imposed on VI are to avoid negative EWT values.

\begin{tabular}{|c|c|c|c|c|c|c|}
\hline MODEL1 (EQ.8) (for LAI > 2) & $\boldsymbol{R}_{1}^{2}$ & RMSE & MODEL2 (EQ.9) (for LAI $\leq 2$ ) & $\boldsymbol{R}_{1}^{2} / \boldsymbol{R}_{2}^{2}$ & RMSE & Conditions \\
\hline$E W T_{C A N-} M O D 1=0.20(N D V I)-0.11$ & $\underline{0.68}$ & $\underline{8}$ & $E W T_{C A N \_} M O D 2=\frac{(N D V I)-0.56}{-7.06(L A I)+20.88}$ & $\underline{0.68 / 0.65}$ & $\underline{7}$ & $\mathrm{NDVI}>0.56$ \\
\hline$E W T_{C A N \_} M O D 1=0.26(E V I)-0.10$ & 0.58 & 10 & $E W T_{C A N_{-}} M O D 2=\frac{(E V I)-0.39}{-8.56(L A I)+22.80}$ & $0.58 / 0.87$ & 6 & $\mathrm{EVI}>0.39$ \\
\hline$E W T_{C A N-} M O D 1=0.14(S A V I)-0.01$ & 0.43 & 18 & $E W T_{C A N-} M O D 2=\frac{(S A V I)-0.04}{-7.41(L A I)+19.19}$ & $0.43 / 0.88$ & 22 & SAVI $>0.07$ \\
\hline$E W T_{C A N-} M O D 1=0.14(M S A V I)+0.02$ & $\underline{0.73}$ & $\underline{7}$ & $E W T_{C A N-} M O D 2=\frac{(M S A V I)+0.17}{-10.39(L A I)+29.68}$ & $\underline{0.73 / 0.76}$ & $\underline{5}$ & MSAVI $>-0.19$ \\
\hline$E W T_{C A N-} M O D 1=0.21(A N D V I)-0.10$ & $\underline{0.73}$ & $\underline{7}$ & $E W T_{C A N \_} M O D 2=\frac{(A N D V I)-0.48}{-6.92(L A I)+19.98}$ & $\underline{0.73 / 0.71}$ & $\underline{6}$ & ANDVI $>0.47$ \\
\hline$E W T_{C A N \_} M O D 1=0.23(N D I I 6)-0.03$ & $\underline{0.71}$ & $\underline{9}$ & $E W T_{C A N-} M O D 2=\frac{(N D I I 6)-0.11}{-3.95(L A I)+12.47}$ & $\underline{0.71 / 0.67}$ & $\underline{8}$ & NDII6 $>0.13$ \\
\hline$E W T_{C A N \_} M O D 1=0.16(N D I I 7)-0.06$ & $\underline{0.73}$ & $\underline{8}$ & $E W T_{C A N \_} M O D 2=\frac{(N D I I 7)-0.38}{-6.98(L A I)+18.81}$ & $0.73 / 0.53$ & 12 & NDII7 > 0.38 \\
\hline$E W T_{C A N-} M O D 1=0.30(G V M I 6)-0.07$ & $\underline{0.63}$ & $\underline{10}$ & $E W T_{C A N-} M O D 2=\frac{(G V M I 6)-0.23}{-2.14(L A I)+7.44}$ & $0.63 / 0.42$ & 10 & GVMI6 > 0.22 \\
\hline$E W T_{C A N-} M O D 1=0.21(G V M I 7)-0.09$ & $\underline{0.71}$ & $\underline{8}$ & $E W T_{C A N \_} M O D 2=\frac{(G V M I 7)-0.45}{-4.78(L A I)+13.00}$ & $0.71 / 0.46$ & 13 & GVMI7 > 0.45 \\
\hline
\end{tabular}
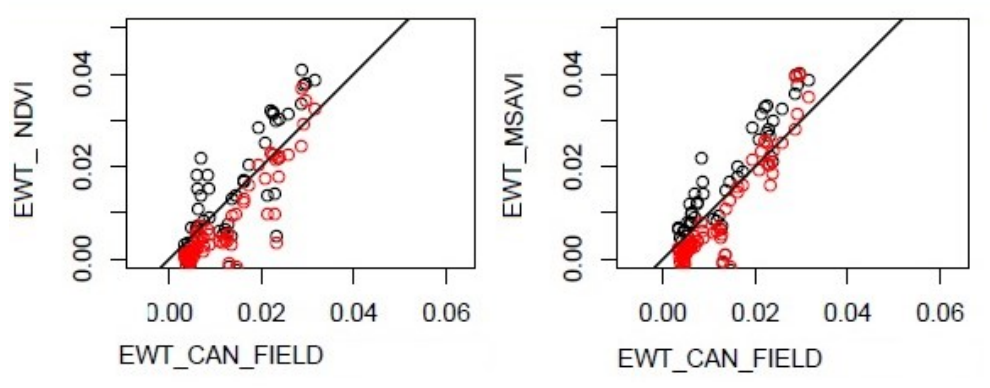
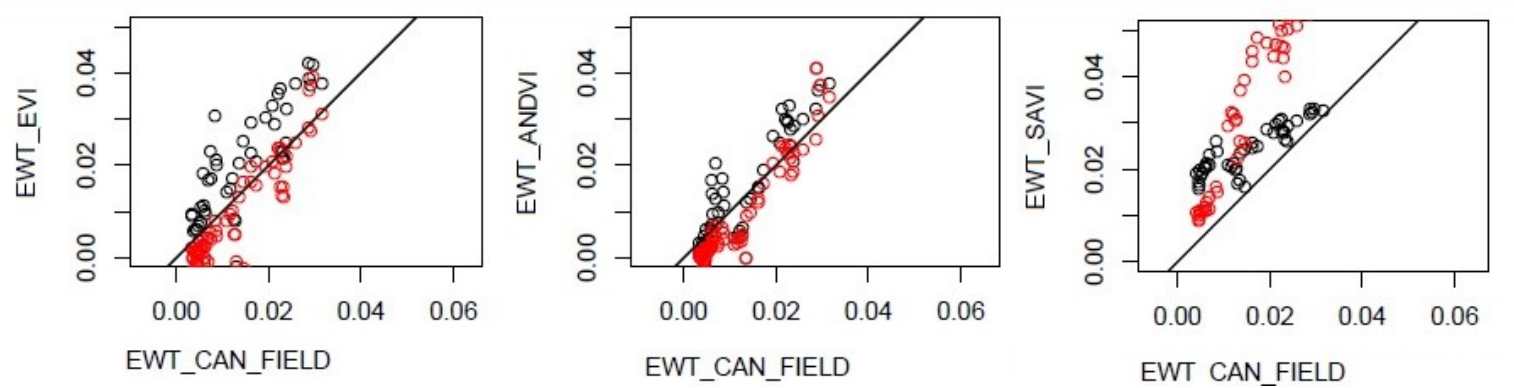

EWT CAN FIELD

Figure 5. Cont. 

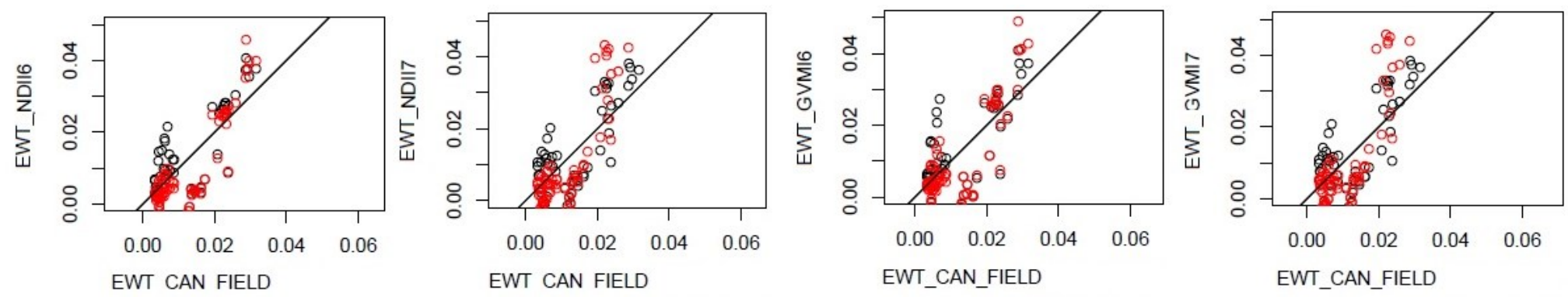

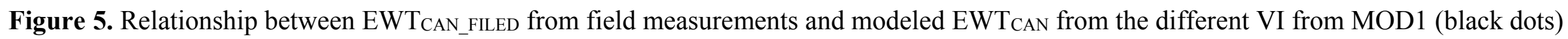
and MOD2 [red dots]). 1:1 line is shown [black line] (EWT $\mathrm{CAN}$ are in $\mathrm{g} \cdot \mathrm{cm}^{-2}$ ).

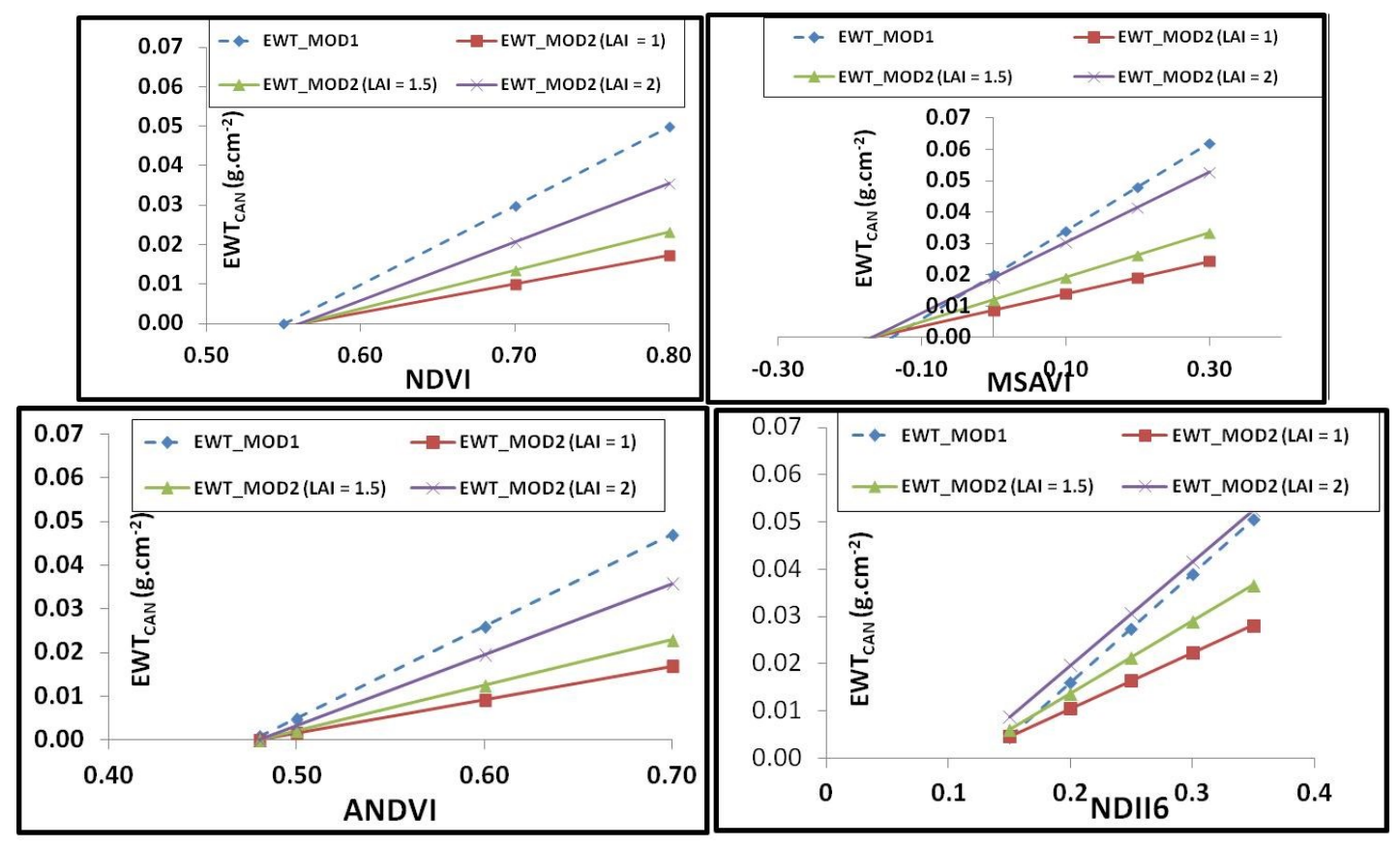

Figure 6. Sparse vegetation effect $(\mathrm{LAI} \leq 2)$ on $\mathrm{EWT}_{C A N}$ inversion models (MOD1, MOD2, $\left.R^{2}>0.60\right)$ from MODIS-VI (NDVI, MSAVI, ANDVI and NDII6) (note that MSAVI could admit negative values). 


\subsection{Regional Analysis of EWT $T_{C A N}$}

From the previously-established models between remotely-sensed VI and estimated EWT CAN from $_{\text {. }}$ ground measurements, we built a multi-temporal set of weekly EWTCAN for the year 2010 based on inversion models using indexes for which both $R_{1}{ }^{2}$ and $R_{2}^{2}$ are high, these indexes are NDVI, MSAVI, ANDVI and NDII6. We explored the effect of LAI integration (MOD2 compared to MOD1) at the regional scale, where EWTCAN were averaged according to two LAI classes (LAI $\leq 1$ and LAI between one and two). Figure 7 shows the varying profiles of EWTCAN along the dry season of the year 2010. For sparse vegetation $(\mathrm{LAI} \leq 1)$, EWT $_{\mathrm{CAN}}$ is almost null because of the high desiccation of the herbaceous layer (Figure 7a) ( $c f$. litter FMC in Figure 2); for LAI between one and two, all inversion models present coherent results with agreement of overestimated values of EWTCAN simulated by MOD1, which does not consider the LAI effect. The EWTCAN time-course from LAI-adapted inversion models (based on significantly related VI to EWTCAN ) is illustrated in Figure 7b (for both LAI between one and two and LAI > 2), showing close profiles resulting from the inversion models based on the various VI (NDVI, ANDVI, MSAVI and NDII6) applied during the dry season (June to September 2010). In summary, the

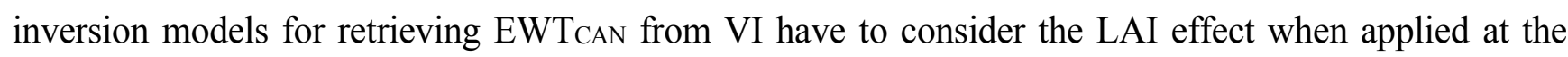
regional scale for $\mathrm{LAI} \leq 2$. On the other hand, for $\mathrm{LAI}>2$, inversion models based on only VI are rather recommended.

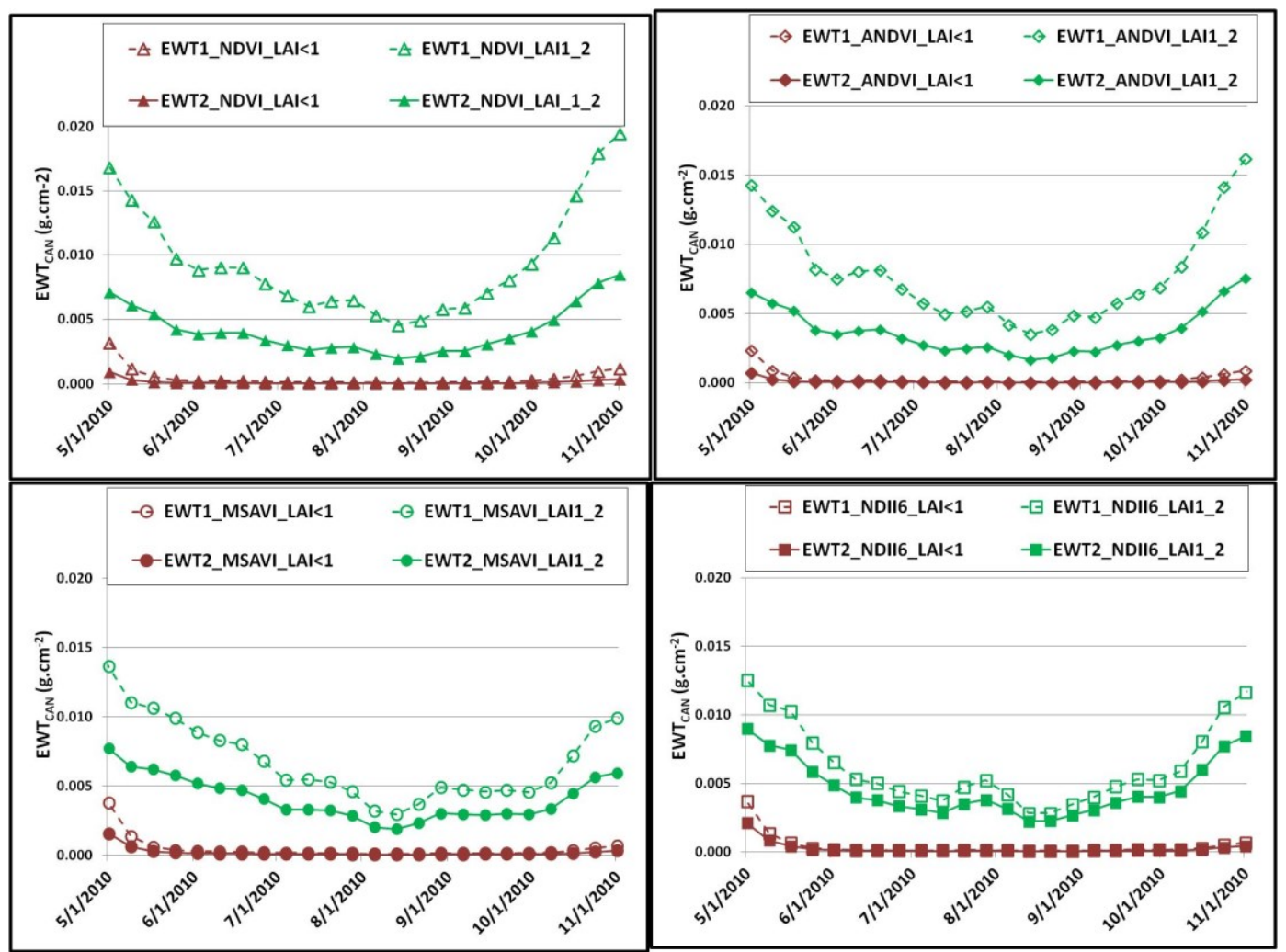

(a)

Figure 7. Cont. 


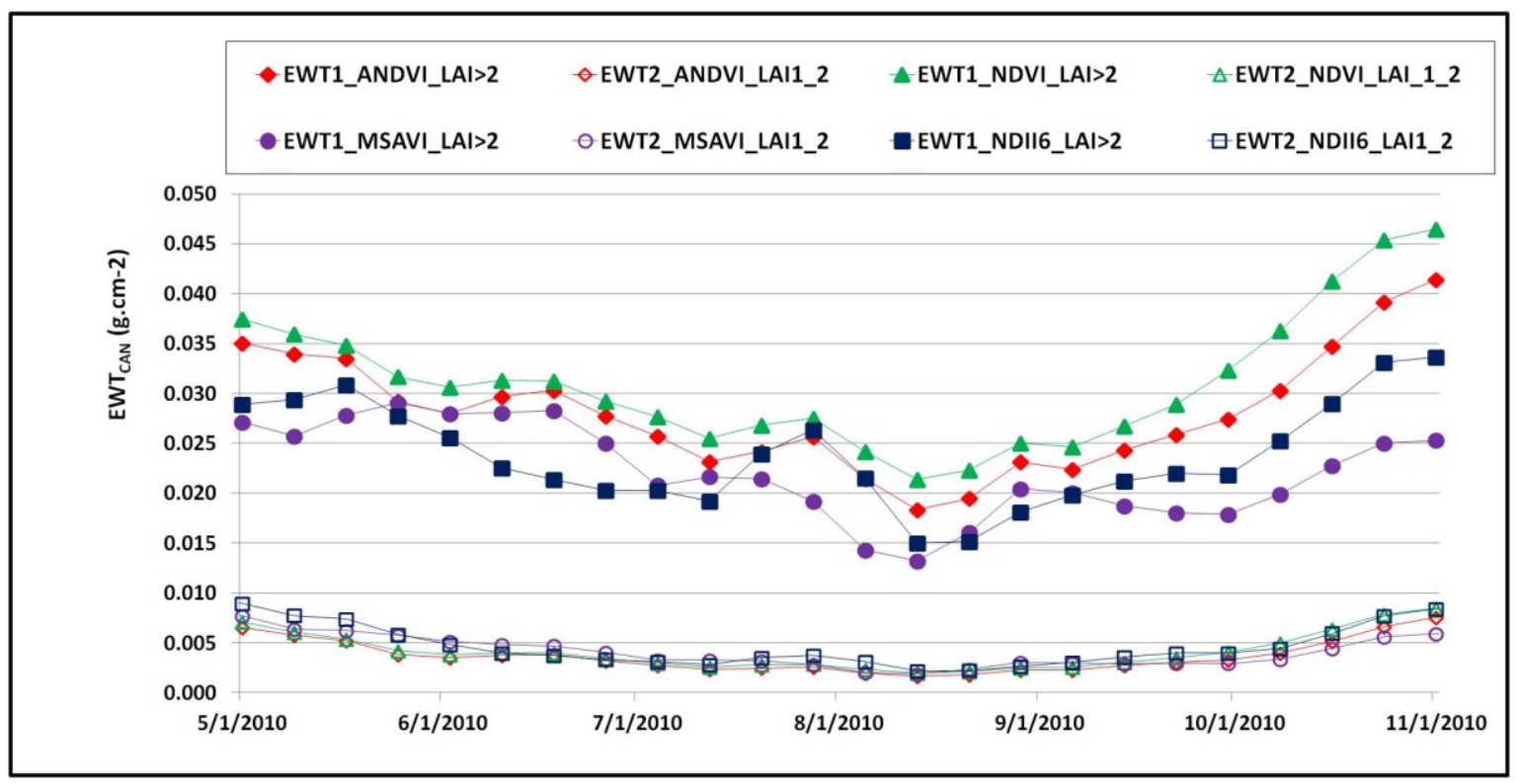

(b)

Figure 7. Time course profiles of EWT $\mathrm{CAN}_{\mathrm{N}}$ as estimated from inversion models, MOD1 (EWT1) and MOD2 (EWT2), using the best performing VI over 2010 in the study region. (a) Comparison of MOD1 and MOD2 for herbaceous (LAI $\leq 1)$ and sparse vegetation (LAI between one and two); (b) comparison of MOD1 and MOD2 for sparse (LAI between one and two) and dense vegetation (LAI > 2).

We finally used EWT CAN from MSAVI (presenting the highest $R_{1}{ }^{2}$ and $R_{2}{ }^{2}$ and the least RMSE at the plot level) to extrapolate the weekly regional mapping of EWT CAN $_{\text {by }}$ applying MOD1 for LAI $>2$ and MOD2 for $\mathrm{LAI} \leq 2$, as stated earlier. We presented the temporal difference in regional EWTCAN for spring, midsummer, end of summer and early fall, four keystone periods for Mediterranean vegetation functioning, representing, respectively, the start and the middle of the dry period, the early end of the dry period, when post-summer storms sporadically happen, and the end of the dry period, when large scale rainfall events refill soil water content up to field capacity. We observed contrasted regional patterns according to the season (Figure $8 \mathrm{a}-\mathrm{d}$ ) and to the topo-climate patterns represented by the digital elevation model (ASTER-GDEM) (Figure 8e).

In spring (Figure 8a), drier conditions appear in the valley bottom, while higher altitudes keep getting wetter. Regression analysis conducted between the spring deficit maps confirms the altitude-dependent effect on the desiccation process with a regression coefficient between spring deficit and altitude maps of 0.70 . This contrasted pattern might be related to the differential evapotranspiration $\left(\mathrm{ET}_{0}\right)$ rates across topographical features [57,58], so that, in the valley bottom, with higher temperatures, $\mathrm{ET}_{0}$ might be higher than rainfall amounts overall, leading to increasing drought, while lower $\mathrm{ET}_{0}$ at higher altitudes do not compensate for water inputs from rainfall. For this period, the regional pattern of drought is then driven by differential $\mathrm{ET}_{0}$ according to topographical effects, rather than the spatial pattern of rainfall. 


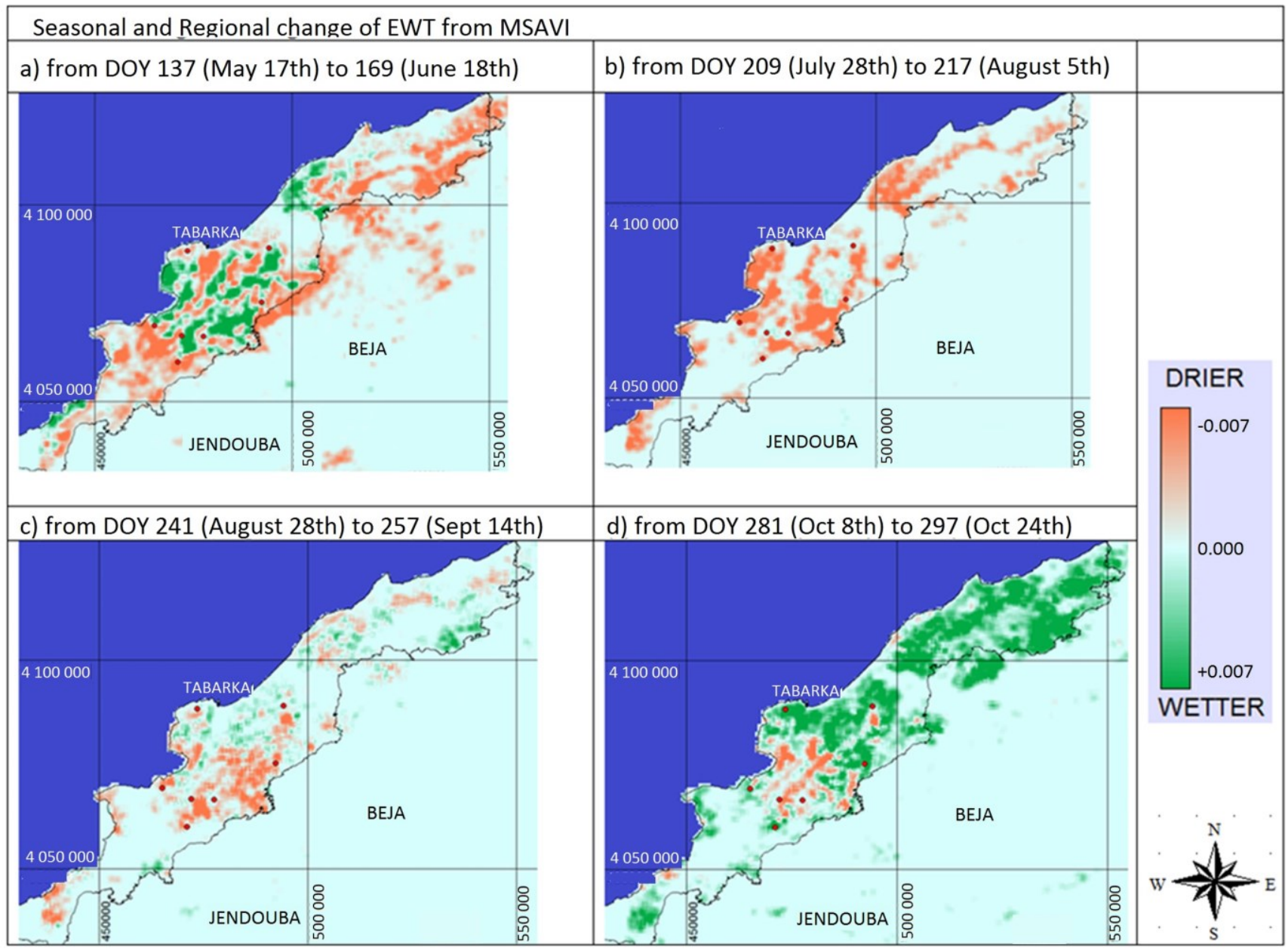

e) Map of altitue from ASTER GDEM

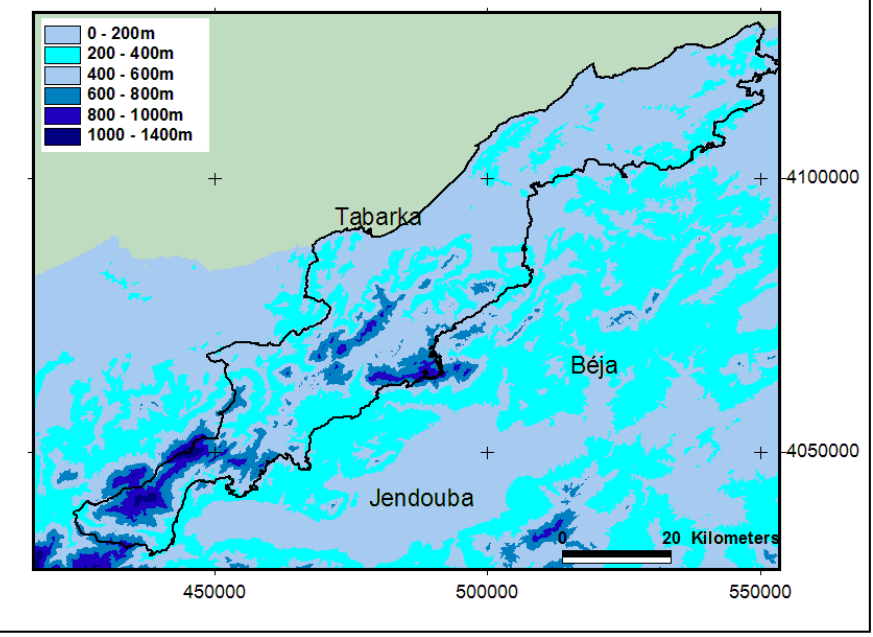

Figure 8. Time course of regional maps of EWTCAN change $\left(\mathrm{g} \cdot \mathrm{cm}^{-2}\right)$ in spring $((\mathbf{a})$; between DOY 137 and 169), mid-summer ((b); between DOY 209 and 217), late summer ((c); between DOY 241 and 257) and early fall ((d); between DOY 281 and 297). Reddish colors indicate drier conditions along the period, and greenish colors indicate wetter conditions along the period. (e) Map of the altitude of the Kroumirie region (processed from ASTER-GDEM). 
In the middle of summer (Figure $8 \mathrm{~b}$ ), the entire region, whatever its topographical situation, is submitted to increasing drought in the absence of any rainfall event. At this time, when drought intensity is at its maximum and soil water content is low, the desiccation pattern is homogenized, as pointed out for Pinus halepensis forest under the Mediterranean climate [59,60].

At the end of summer (end of August) (Figure 8c), sporadic rainfalls start to happen, mostly dominated by a west/north incoming wet air mass from the Mediterranean Sea warmed up by the summer season high temperatures. The altitude-dependent effect on rewetting is also present, with a regression coefficient between end of summer deficit and altitude maps of 0.67. The Atlas Mountains act as a barrier to cloud movements, leading to rainfall pouring only on the northern part of the region, while the most southern hills remain dry [61]. We indeed observe a rewetting of the northern part of the region (green) from remote sensing for this period, while the most southern part of the region keeps drying off. During this period of the year, low intensity rainfalls $(<10 \mathrm{~mm})$, more sporadic than large-scale heavy events, can lead to short-term pulses with a significant impact on ecosystem water budgets [62]. We observed here a contrasted pattern with a significant boundary between the rainfall-affected and non-affected parts of the region.

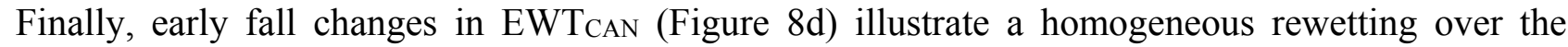
whole region, except high altitudes potentially already filled up to field capacity at that time and not submitted to rewetting.

This seasonal pattern of desiccation/rewetting with a high spatial resolution brings useful information for drought monitoring and forest management trough impact assessments on local-scale forest functioning [63-65], tree mortality [59,66] or fire risk [67]. More particularly, this information brings fine-scale information on the spatial pattern of drought, hardly precisely assessed from rough interpolations of meteorological variables [68], particularly when rain gauges are sparse, as in Tunisia [69] and more generally in Africa [70], and still uncertain from global-scale remote sensing [71-73].

\section{Conclusions}

This study investigated the suitability of biomass and moisture vegetation indexes for vegetation water content expressed by the equivalent water thickness for Mediterranean vegetation across a tree cover LAI gradient with contrasted water budgets and desiccation rates. We proposed peculiar adjustments for low LAI and tree cover ecosystems. First, the comparison of remote sensing (MODIS) to vegetation water content required a formulation of EWT at the canopy level that had to consider the mixture of plant functional types for water use (trees, shrubs and herbaceous layers) and a varying vegetation cover. The performance of moisture indexes (computed from NIR and SWIR) was comparable ( $R^{2}$ from 0.65 to 0.76 ), whereas for biomass vegetation indexes, MSAVI and ANDVI performed better than NDVI, EVI and SAVI ( $R^{2}$ from 0.43 to 0.73 ). We particularly demonstrated and

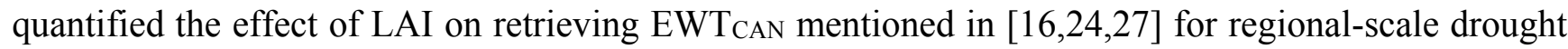
assessment under a tree cover/LAI gradient from dense to open forest. LAI adaptive inversion models for retrieving EWT $_{\mathrm{CAN}}$ are then proposed for Mediterranean forests drought monitoring by the VI/LAI inversion model for moderately-covered areas and the VI inversion model for denser forests. The regional scale investigation of EWT CAN $_{\text {in }} 2010$ derived from the MSAVI/LAI inversion model (for which we found the best linear fits) revealed the temporal changes in regional patterns of ecosystem 
desiccation and rewetting along the summer season, including late summer rainfall pulses with scattered patterns. This integrated approach offered a fine-scale drought assessment for forest management when rainfall gauges are sparse and fine-scale topo-climates are hardly quantified.

\section{Acknowledgments}

This study was partly funded by the "Ministère des Affaires étrangères" (France) Coopération pour la Recherche Universitaire et Scientifique (CORUS2) project and EU FP7 program FUME "Forest Fires under Climate, Social and Economic changes in Europe, the Mediterranean and other fire-affected areas of the world" Contract Grant No. 243888. We thank NASA Earth Science Enterprise for providing free MODIS images on the web.

\section{Author Contributions}

Hedia Chakroun performed MODIS processing, analysis and modeling. Florent Mouillot performed the experimental design, statistical analysis and modeling. Abdelaziz Hamdi performed the experimental design and field data collection. Hedia Chakroun and Florent Mouillot equally contributed to the writing of the manuscript.

\section{Conflicts of Interest}

The authors declare no conflict of interest.

\section{References}

1. Atzberger, C. Advances in remote sensing of agriculture: Context description, existing operational monitoring systems and major information needs. Remote Sens. 2013, 5, 949-981.

2. Vicente-Serrano, S.M.; Gouveia, C.; Camareno, J.J.; Begueria, S.; Trigo, R.; Lopez-Moreno, J.I.; Azorin-Molina, C.; Pasho, E.; Lorenzo-Cruz, J.; Revuelto, J.; et al. Response of vegetation to drought time scales across global land biomes. Proc. Natl. Acad. Sci. USA 2013, 110, 52-57.

3. Zhao, M.; Running, S.W. Drought-induced reduction in global terrestrial net primary production from 2000 through 2009. Science 2010, 329, 940-943.

4. Yebra, M.; Dennison, P.E.; Chuvieco, E.; Riaño, D.; Zylstra, P.; Hunt, E.R.; Danson, M.; Qi, Y.; Jurado, S.A. A global review of remote sensing of live fuel moisture content for fire danger assessment: Moving towards operational products. Remote Sens. Environ. 2013, 136, 455-468.

5. Dai, A. Drought under global warming: A review. Wiley Interdiscip. Rev. Clim. Chang. 2010, 2, $45-65$.

6. Qi, Y.; Dennison, P.E.; Jolly, M.W.; Kropp, R.C.; Brewer, S.C. Spectroscopic analysis of seasonal changes in live fuel moisture content and leaf dry mass. Remote Sens. Environ. 2014, 150, 198-206.

7. Qi, Y.; Dennison, P.E.; Spencer, J.; Riaño, D. Monitoring live fuel moisture using soil moisture and remote sensing proxies. Fire Ecol. 2012, 8, 71-87. 
8. Roberts, D.A.; Dennison, P.E.; Peterson, S.; Sweeney, S.; Rechel, J. Evaluation of aviris and modis measures of live fuel moisture and fuel condition in a shrubland ecosystem in southern california. J. Geophys. Res. Biogeosci. 2006, 111, doi:10.1029/2005JG000113.

9. Stow, D.; Niphadkar, M.; Kaiser, J. Time series of chaparral live fuel moisture maps derived from modis satellite data. Int. J. Wildland Fire 2006, 15, 361-374.

10. Caccamo, G.; Chisholm, L.A.; Bradstock, R.A.; Puotinen, M.L. Assessing the sensitivity of modis to monitor drought in high biomass ecosystems. Remote Sens. Environ. 2011, 115, 2626-2639.

11. Zarco-Tejada, P.J.; Rueda, C.A.; Ustin, S.L. Water content estimation in vegetation with modis reflectance data and model inversion methods. Remote Sens. Environ. 2003, 85, 109-124.

12. Gao, Z.; Zhang, W.; Gao, W.; Chang, N.B. Modeling the land surface heat exchange process with the aid of moderate resolution imaging spectroradiometer images. J. Appl. Remote Sens. 2009, 3, doi:10.1117/1.3290811.

13. Ceccato, P.; Flasse, S.; Tarantola, S.; Jacquemoud, S.; Gregoire, J.M. Detecting vegetation leaf water content using reflectance in the optical domain. Remote Sens. Environ. 2001, 77, 22-33.

14. Fensholt, F.; Sandholt, I. Derivation of a shortwave infrared water stress Index from modis near and shortwave infrared data in a semiarid environment. Remote Sens. Environ. 2003, 87, 111-121.

15. Gao, B.C. Ndwi-A normalized difference water index for remote sensing of vegetation liquid water from space. Remote Sens. Environ. 1996, 58, 257-266.

16. Huete, A.; Didan, K.; Miura, T.; Rodriguez, E.P.; Gao, X.; Ferreira, L.G. Overview of the radiometric and biophysical performance of the modis vegetation Indexs. Remote Sens. Environ. 2002, 83, 195-213.

17. Huete, A.R. A soil adjusted vegetation index (savi). Remote Sens. Environ. 1988, 25, 295-309.

18. Qi, J.A. A modified soil adjusted vegetation index. Remote Sens. Environ. 1994, 48, 119-126.

19. Liu, Z.Y.; Huang, J.F.; Wang, F.M.; Wang, Y. Adjusted-normalized difference vegetation Index for estimating leaf area Index of rice. Sci. Agric. Sin. 2008, 41, 3350-3356.

20. Ceccato, P.; Gobron, N.; Flasse, S.; Pinty, B.; Tarantola, S. Designing a spectral Index to estimate vegetation water content from remote sensing data: Part 1. Theoretical approach. Remote Sens. Environ. 2002, 82, 188-197.

21. Hunt, E.R.; Li, L.; Yilmaz, L.T.; Jackson, T.J. Comparison of vegetation water contents derived from shortwave-infrared and passive-microwave sensors over central iowa. Remote Sens. Environ. 2011, 115, 2376-2383.

22. Gao, B.C.; Goetz, A.F.H. Retrieval of equivalent water thickness and information related to biochemical components of vegetation canopies for aviris data. Remote Sens. Environ. 1995, 52, $155-162$.

23. Datt, B. Remote sensing of water content in eucalyptus leaves. Aust. J. Bot. 1999, 47, 909-923.

24. Barraza, V.; Grings, F.; Ferrazzoli, P.; Salvia, M.; Maas, M.; Rahmoune, R.; Vittucci, C.; Karszenbaum, H. Monitoring vegetation moisture using passive microwave and optical Indexs in the dry chaco forest, argentina. IEEE J. Sel. Top. App. Earth Obs. Remote Sens. 2013, 7, 421-430.

25. Rouse, J.W.; Haas, R.H.; Schell, J.A.; Deering, D.W. Monitoring Vegetation Systems in the Great Plains with ERTS. In Third ERTS Symposium; NASA: Washington, DC, USA, 1973; Volume SP 351 I, pp 309-317. 
26. Tucker, C.J. Red and photographic infrared linear combinations for monitoring vegetation. Remote Sens. Environ. 1979, 8, 127-150.

27. Hardisky, M.A.; Klemas, V.; Smart, R.M. The influence of soil salinity, growth form, and leaf moisture on the spectral radiance of spartina alterniflora canopies. Photog. Eng. Remote Sens. 1983, 49, 77-83.

28. Hunt, E.R.; Rock, B.N. Detection of changes in leaf water content using near and middle-infrared reflectances. Remote Sens. Environ. 1989, 30, 43-54.

29. Chuvieco, E.; Riaño, D.; Aguado, I.; Cocero, D. Estimation of fuel moisture content from multitemporal analysis of landsat thematic mapper reflectance data: Applications in fire danger assessment. Int. J. Remote. Sens. 2002, 23, 2145-2162.

30. Peterson, S.; Roberts, D.A.; Dennison, P.E. Mapping live fuel moisture with modis data: A multiple regression approach. Remote Sens. Environ. 2008, 112, 4272-4284.

31. Yebra, M.; Chuvieco, E.; Riaño, D. Estimation of live fuel moisture content from modis images for fire risk assessment. Agric. For. Meteorol. 2008, 148, 523-536.

32. Ceccato, P.; Flasse, S.; Gregoire, J.M. Designing a spectral Index to estimate vegetation water content from remote sensing data: Part 2. Validation and applications. Remote Sens. Environ. 2002, 82, 198-207.

33. Sow, M.; Mbow, C.; Hely, C.; Fensholt, R. Estimation of herbaceous fuel moisture content using vegetation Indexs and land surface temperature from MODIS data. Remote Sens. 2013, 5, 2617-2638.

34. Cheng, Y.B.; Ustin, S.L.; Riaño, D.; Vanderbilt, V.C. Water content estimation from hyperspectral images and modis Indexs in southeastern arizona. Remote Sens. Environ. 2008, 112, 363-374.

35. Caccamo, G.; Chisholm, L.A.; Bradstock, R.A.; Puotinen, M.L.; Pippen, B.G. Monitoring live fuel moisture content of heathland, shrubland and sclerophyll forest in south-eastern australia using modis data. Int. J. Wildland Fire 2012, 21, 257-269.

36. Danson, F.M.; Bowyer, P. Estimating live fuel moisture content from remotely sensed reflectance. Remote Sens. Environ. 2004, 92, 309-321.

37. Kochendorfer, J.P.; Ramırez, J.A. Modeling the monthly mean soil water balance with a statistical-dynamical ecohydrology model as coupled to a two-component canopy model. Hydrol. Earth Syst. Sci. 2010, 14, 2099-2120.

38. Jacquemoud, S.; Baret, F. Prospect: A model of leaf optical properties spectra. Remote Sens. Environ. 1990, 34, 75-91.

39. Roberts, D.A.; Ustin, S.L.; Ogunjemiyo, S.; Greenberg, J.; Dobrowski, S.Z.; Chen, J.; Hinckley, T.M. Spectral and structural measures of northwest forest vegetation at leaf to landscape scales. Ecosystems 2004, 7, 545-562.

40. Sims, D.A.; Gamon, J.A. Estimation of vegetation water content and photosynthetic tissue area from spectral reflectance: A comparison of Indexs based on liquid water and chlorophyll absorption features. Remote Sens. Environ. 2003, 84, 526-537.

41. Réseau Hydrique. Available online: http://www.reseau-hydrique.org (accessed on 17 December 2014). 
42. Hmimina, G.; Dufrêne, E.; Pontailler, J.Y.; Delpierre, N.; Aubinet, M.; Caquet, B.; Grandcourt, A.D.; Burban, B.; Flechard, C.; Granier, A.; et al. Evaluation of the potential of modis satellite data to predict vegetation phenology in different biomes: An investigatioon using groudn based ndvi measurements. Remote Sens. Environ. 2013, 132, 145-158.

43. NASA's Earth Observing System Date and Information System. Available online: http://reverb.echo.nasa.gov (accessed on 17 December 2014).

44. Chakroun, H.; Mouillot, F.; Nasr, Z.; Nouri, M.; Ennajah, A.; Ourcival, J.M. Performance of lai-modis and the influence on drought simulation in a mediterranean forest. Ecohydrology 2014, 7, 1014-1028.

45. Eklundh, L.; Jönsson, P. Timesat 3.0 Software Manual. Available online: http://www.nateko.lu.se/ TIMESAT/docs/timesat30_software_manual.pdf (accessed on 17 December 2014).

46. Jönsson, P.; Eklundh, L. Seasonality extraction and noise removal by function fitting to time series of satellite sensor data. IEEE Trans. Geosci. Remote Sens. 2002, 40, 1824-1832.

47. Savitzky, A.; Golay, M.J.E. Smoothing and differentiation of data by simplified least squares procedures. Anal. Chem. 1964, 36, 1627-1639.

48. Choler, P.; Sea, W.; Briggs, P. A simple ecohydrological model captures essentials of seasonal leaf dynamics in semi-arid tropical grasslands. Biogeosciences 2010, 7, 907-920.

49. Hird, J.N.; McDermid, G.J. Noise reduction of ndvi time series: An empirical comparison of selected techniques. Remote Sens. Environ. 2009, 113, 248-258.

50. Yilmaz, M.T.; Hunt, E.R.; Jackson, T.J. Remote sensing of vegetation water content from equivalent water thickness using satellite imagery. Remote Sens. Environ. 2008, 112, 2514-2522.

51. Pellizzaro, G.; Cesaraccio, C.; Duce, P.; Ventura, A.; Ara, P.Z. Relationship between seasonal patterns of live fuel moisture and meteorological drought Indexs for mediterranean shrubland species. Int. J. Wildland Fire 2007, 16, 232-241.

52. Chuvieco, E.; Gonzalez, I.; Verdu, F.; Aguado, I.; Yebra, M. Prediction of fire occurrence from live fuel moisture content measurements in a mediterranean ecosystem. Int. J. Wildland Fire 2009, 18, 430-441.

53. Saura-Mas, S.; Lloret, F. Leaf and shoot water content and leaf dry matter content of mediterranean woody species with different post fire regenerative strategies. Ann. Bot. 2007, 99, 545-554.

54. Poorter, H.; Niinemets, U.; Poorter, L.; Wright, I.J.; Villar, R. Causes and consequences of variation in leaf mass per area (lma): A meta-analysis. New Phytol. 2009, 182, 565-588.

55. Ma, S.; Baldocchi, D.D.; Mamballi, S.; Dawson, T.E. Are temporal variations of leaf traites responsible for seasonal and interannual variability in ecosystems co2 exchange? Funct. Ecol. 2011, 25, 258-270.

56. Fioretto, A.; Papa, S.; Pellegrino, A.; Fuggi, A. Decomposition dynamics of myrtus communis and querucs ilex leaf litter: Mass loss, microbial activity and quality change. Appl. Soil Ecol. 2007, 36, 32-40.

57. Shevenell, L. Regional potential evapotranspiration in arid climates based on temperature, topography and calculated solar radiation. Hydrol. Proc. 1999, 13, 577-596. 
58. Mitchell, P.J.; Benyon, R.G.; Lane, P.N.J. Responses of evapotranspiration at different topographic positions and catchment water balance following a pronounced drought in a mixed species eucalypt forest, australia. J. Hydrol. 2012, 440-441, 62-74.

59. Dorman, M.; Svoray, T.; Perevolotsky, A. Homogenization in forest performance across an environmental gradient-The interplay between rainfall and topographic aspect. For. Ecol. Manag. 2013, 310, 256-266.

60. Volcani, A.; Karnieli, A.; Svoray, T. The use of remote sensing and gis for spatio-temporal analysis of the physiological state of a semi arid forest with respect to drought years. For. Ecol. Manag. 2005, 215, 239-250.

61. Slimani, M.; Cudennec, C.; Feki, H. Structure of the rainfall gradient in the mediterranean-Sahara transition in tunisia: Geographical determinants and seasonality. Hydro. Sci. J. 2007, 52, $1088-1102$.

62. Longepierre, D.; Mouillot, F.; Ouelhazi, B.; Ourcival, J.M.; Rocheteau, A.; Degueldre, D.; Rejeb, M.N. True water constraint under a rainfall interception experiment in a mediterranean shrubland (northern tunisia): Confronting discrete measurements with a plant-soil water budget model. Plant Ecol. 2014, 215, 779-794.

63. Garten, C.T.; Taylor, G.E. Foliar dc13 within a temperate deciduous forest: Spatial, temporal and species sources of variation. Oecologia 1992, 90, 1-7.

64. Petroselli, A.; Vessella, F.; Cavagnuolo, L.; Piovesan, G.; Schirone, B. Ecological behavior of quercus suber and quercus ilex inferred by topographic wetness index (twi). Trees 2013, 27, 1201-1215.

65. Liancourt, P.; Spence, L.A.; Song, D.S.; Lkhagva, A.; Boldgiv, B.; Helliker, R.; Petraitis, P.S.; Casper, B.B. Plant response to climate change variy with topography; interactions with neighbors and ecotype. Ecology 2013, 94, 444-453.

66. Costa, A.; Pereira, H.; Madeira, M. Analysis of spatial patterns of oak decline in cork oak woodlands in mediterranean conditions. Ann. For. Sci. 2010, 67, doi:10.1051/forest/2009097.

67. Chuvieco, E.; Cocero, D.; Riano, D.; Martin, P.; Martınez-Vega, J.; Riva, J.D.L.; Perez, F. Combining ndvi and surface temperature for the estimation of live fuel moisture content in forest fire danger rating. Remote Sens. Environ. 2004, 92, 322-331.

68. Bedia, J.; Herrera, S.; Gutierrez, J.M. Dangers in using global bioclimatic datasets for ecological niche modeling. Limitations for future climate projections. Glob. Plan. Chang. 2013, 107, 1-12.

69. Meroni, M.; Marinho, E.; Sghaier, N.; Verstrate, M.M.; Leo, O. Remote sensing based yield estimation in a stochastic framework-Case study of durum wheat in tunisia. Remote Sens. 2013, 5, 539-557.

70. Anderson, W.B.; Zaitchik, B.F.; Hain, M.C.; Anderson, M.C.; Yilmaz, M.T.; Mecikalski, J.; Schultz, L. Towards and integrated soil moisture drought monitor for east africa. Hydrol Earth Syst. Sci. 2012, 16, 2893-2913.

71. Katiraie-Boroujerdy, P.S.; Nasrollahi, N.; Hsu, K.L.; Sorrooshian, S. Evaluation of satellite based precipitation estimation over iran. J. Arid Environ. 2013, 97, 205-219.

72. Gebregiorgis, A.S.; Hossain, F. Understanding the dependence of satellite rainfall uncertainty on topography and climate for hydrologic model simulation. IEEE Trans. Geosci. Remote Sens. 2013, 51, 704-718. 
73. Bytheway, J.L.; Kummerow, C.D. Inferring the uncertainty of satellite precipitation estimates in data-sparse regions over land. J. Geophys. Res.: Atmos. 2013, 118, 9524-9533.

(C) 2015 by the authors; licensee MDPI, Basel, Switzerland. This article is an open access article distributed under the terms and conditions of the Creative Commons Attribution license (http://creativecommons.org/licenses/by/4.0/). 